


\section{Processing of maize plants to produce sugars or cellulose pulp}

Authors: Paulien Harmsen, Edwin Keijsers, Brigit Beelen

With cooperation of Richard Op den Kamp, Mario van Wandelen, Jeroen van Bon.

This research project has been carried out by Wageningen Food \& Biobased Research commissioned by the Dutch Ministry of Agriculture, Nature and Food Quality (project number 6224066200). 
Version: final

Reviewer: Johan van Groenestijn

Approved by: Jan Jetten

Client: the Dutch Ministry of Agriculture, Nature and Food Quality

This report can be downloaded for free at https://doi.org/10.18174/527984 or at www.wur.eu/wfbr (under publications).

(C) 2020 Wageningen Food \& Biobased Research, institute within the legal entity Stichting Wageningen Research.

The client is entitled to disclose this report in full and make it available to third parties for review. Without prior written consent from Wageningen Food \& Biobased Research, it is not permitted to:

a. partially publish this report created by Wageningen Food \& Biobased Research or partially disclose it in any other way;

b. (let a third party) use this report created by Wageningen Food \& Biobased Research or the name of the report or Wageningen Food \& Biobased Research in whole or in part for the purposes of making claims, conducting legal procedures, for (negative) publicity, and for recruitment in a more general sense;

c. use the name of Wageningen Food \& Biobased Research in a different sense than as the author of this report.

PO box 17, 6700 AA Wageningen, The Netherlands, T + 31 (0)317 4800 84, E info.wfbr@wur.nl, www.wur.eu/wfbr. Wageningen Food \& Biobased Research is part of Wageningen University \& Research.

All rights reserved. No part of this publication may be reproduced, stored in a retrieval system of any nature, or transmitted, in any form or by any means, electronic, mechanical, photocopying, recording or otherwise, without the prior permission of the publisher. The publisher does not accept any liability for inaccuracies in this report. 


\section{Summary}

Three genotypes of maize plants were provided by Wageningen Plant Research (Ambrosini, 10LG and $5 \mathrm{LG})$, varying in composition hemicellulose/cellulose/lignin. The samples were tested for their suitability as resource to produce sugars for fermentation or for the production of a cellulose pulp.

After harvesting and cutting of the maize plants, a heterogeneous mixture of stems and leaves was obtained with various particle sizes/thicknesses. Compared to other lignocellulosic biomasses the samples contained a high amount of water-soluble extractives, most likely due to soluble sugars that are present in the stems. The Ambrosini genotype contained the highest amount of lignin, 5LG sample the lowest.

\section{Fermentable sugars}

All three genotypes were subjected to an acid pretreatment at 130 or $160^{\circ} \mathrm{C}$, followed by enzymatic hydrolysis with a mixture of cellulases and hemicellulases. The treatment at $160{ }^{\circ} \mathrm{C}$ resulted in higher glucose and xylose yield compared to $130^{\circ} \mathrm{C}$, and especially for xylose the differences were large. Overall, genotype 5LG resulted in the lowest sugar yield, while genotype $10 \mathrm{LG}$ gave the highest yield. Acid treatment of $10 \mathrm{LG}$ at $160^{\circ} \mathrm{C}$ followed by enzymatic hydrolysis gave the highest yield, $24 . \mathrm{g}$ glucose and $16.4 \mathrm{~g}$ xylose per $100 \mathrm{~g}$ dry maize. At mild pre-treatment severity, the higher lignin content made Ambrosini the least digestible genotype. 10LG and 5LG were better digestible.

From this part of the study it was concluded that maize plants are an interesting source of sugars, especially when the free sugars (found in the extractives) are included. It was recommended to extract the water-soluble sugars first to prevent sugar degradation of these free sugars in the pretreatment step. A subsequent acid pretreatment followed by enzymatic hydrolysis resulted in overall high yields of sugars (80-90 wt\%), leading to a theoretical sugar yield of approximately 50 wt $\%$ of the original maize biomass.

\section{Cellulose pulp}

Another part of the study was the conversion of the maize plants to cellulose pulp by four different methods: prehydrolysis followed by organosolv, acid super heated steam (SHS), alkaline super heated steam, and alkaline pulping at $120^{\circ} \mathrm{C}$. Genotype 5LG was selected because of its low lignin and high cellulose content.

Retention of cellulose in the samples was the highest for the acid SHS treatment (91\%), but also the alkaline treatments resulted in a high retention of cellulose $(81 \%)$. For removal of hemicellulose, the acid SHS treatment was by far the most efficient one. Under these conditions, only $4 \%$ of the hemicellulose remained in the sample and more than $90 \%$ was removed by the treatment. Cellulose content of the samples was $65 \mathrm{wt} \%$ for the acid-SHS treatment, and $58 \mathrm{wt} \%$ for the alkaline treatments, still far from $>90$ wt $\%$ cellulose content required for a dissolving cellulose pulp.

\section{Hand sheets}

The fibre properties of the cellulose pulps, the mechanical and physical properties of hand sheets were determined to get insight in the morphology of the cellulose pulps after chemical treatment, and on the performance for application in paper products.

Results showed that the acid-SHS treatment was less effective in breaking down the fibre bundles of the maize biomass into fibres compared to the alkaline treatments. The acid treated maize pulp was not fully disintegrated into fibres, resulting in a high bulk value. Also, the bulk levels of the alkaline treated pulps were at the higher side of chemical wood pulps, showing that the pulping treatments applied in this study were less severe than conventional chemical pulping treatments of commercial pulps. 


\section{Overall conclusions}

The value of cellulose pulps from maize stems and leaves was compared to commercial wood pulps and pulps made from nature grass. Overall, the quality of the maize pulps was low, and especially the acid-SHS treated samples had a very poor quality.

Based on this study it was concluded that acid-based treatment processes are preferred for the production of sugars from maize stems and leaves, and that alkaline treatments are most suitable for the production of cellulose pulp. Genotype 5LG resulted in the lowest sugar yield, while genotype $10 \mathrm{LG}$ gave the highest yield.

A second conclusion was that maize plants are a good biomass source for the production of sugars (particularly the 10LG genotype) and less suited for the production of a cellulose pulp. 


\section{Contents}

Summary $\quad 3$

$\begin{array}{llr}1 & \text { Introduction } & 7\end{array}$

2 Materials and methods $\quad 9$

2.1 Materials $\quad 9$

2.2 Pretreatment methods $\quad 9$

2.2.1 Acid hydrolysis and enzymatic hydrolysis 9

2.2.2 Prehydrolysis with water and organosolv pulping $\quad 10$

2.2.3 Acid soaking and superheated steam treatment $\quad 10$

2.2.4 Alkaline soaking and superheated steam treatment $\quad 10$

2.2.5 Alkaline pulping in 50L conical screw reactor $\quad 11$

$\begin{array}{lll}2.3 & \text { Analysis methods } & 11\end{array}$

2.3.1 Chemical composition maize biomass 11

2.3.2 Enzymatic kits for glucose and xylose 12

2.3.3 Fibre properties $\quad 12$

$3 \quad$ Results and discussion $\quad 13$

3.1 Chemical composition of maize biomass 13

3.2 Cellulose pulp from maize stems and leaves 13

$\begin{array}{lll}3.2 .1 & \text { Introduction } & 13\end{array}$

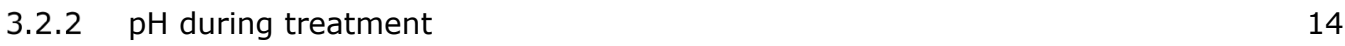

3.2.3 Pulping yield 14

3.2.4 Chemical composition after treatment 15

3.2.5 Mass balances 16

3.2.6 Fibre properties of cellulose pulps 18

3.2.7 Mechanical properties of hand sheets 18

3.2.8 Physical properties of hand sheets $\quad 19$

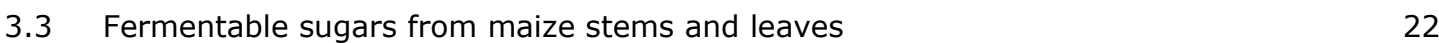

$\begin{array}{lll}3.3 .1 & \text { Introduction } & 22\end{array}$

3.3.2 Enzymatic hydrolysis of acid hydrolysed samples $\quad 22$

3.3.3 Enzymatic hydrolysis of cellulose pulps 24

$\begin{array}{llr}4 & \text { Conclusions and recommendations } & 27\end{array}$

$\begin{array}{lll}\text { Annex } 1 & \text { Physical properties of the hand sheets } & 29\end{array}$ 


\section{Introduction}

Wageningen UR investment program Resource Use Efficiency (RUE) was funded by the Dutch Ministry of Economic affairs. Efficient use of biomass was one of the topics, and in this project the use of maize plants as biomass source for the production of sugar and cellulose pulp was investigated.

Two main research questions were studied:

- Is there a difference in suitability to produce fermentable sugars and cellulose pulp between maize genotypes with different digestibility as a feed?

- Which process is most suited to process the maize genotypes into fermentable sugars or cellulose pulp?

Freshly harvested maize plants (stems and leaves) of three genotypes (Ambrosini, 10LG 30248 and 5LG 30218-bm) were kindly provided by Wageningen Plant Research (WPR). All three genotypes were tested for their suitability as resource to produce fermentable sugars. An acid-based two-stage process was applied as shown in Figure 1:

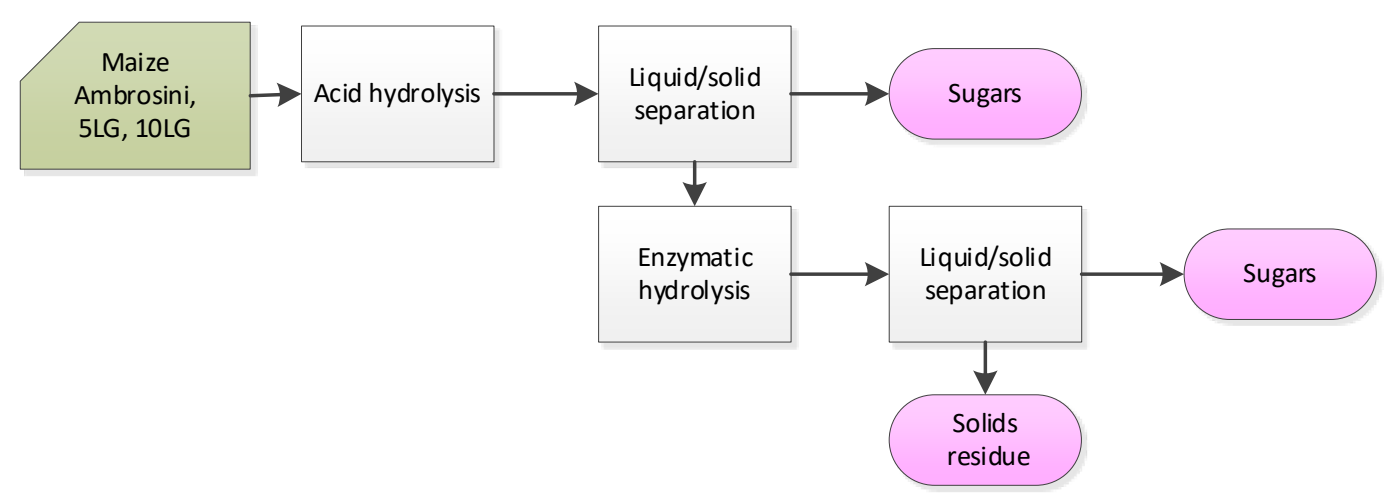

Figure 1 Consecutive acid and enzymatic hydrolysis process to produce sugars

In addition, four other pulping or pretreatment processes were tested (see Figure 2) on one selected maize genotype (5LG 30218-bm) with a dual objective:

- To apply as pretreatment for the enzymatic hydrolysis to establish the amount of fermentable sugars that could be produced (with the above-mentioned acid hydrolysis as base case).

- To evaluate the four pretreatment processes as the first stage of a process to produce cellulose pulp, an intermediate product to produce dissolving cellulose. The whole process to produce dissolving cellulose consists of several steps, including bleaching stages following these first pulping stages. In this study, only the first stage of the production of dissolving cellulose was evaluated, i.e. the extraction of a crude cellulose fraction from biomass by pulping.

Rationale behind this is to study the different modes of action of these four pulping processes. The first and fourth process in Figure 2 are very suitable to produce dissolving cellulose as lignin is (partly) dissolved in the liquid phase and molecular weight of cellulose remains intact. Dissolving cellulose pulp (cellulose pulp with a high purity and high molecular weight) has a good market value. Once dissolved it can be spun into fibres for textile (e.g. viscose) or chemically modified to thermoplastic celluloses (like cellulose acetate) with an even higher market value. Currently, wood and cotton are the main sources for dissolving pulp. Energy demanding- and sulphur containing pulping processes are applied, and in most cases, chlorine is used in purification steps for delignification of the pulp. Additional purification steps like bleaching or washing are needed to obtain a pulp with desired properties. The second and third process are more suitable to produce (fermentable) sugars. Here the sugars are dissolved in the liquid phase and lignin is discarded as a solid residue. 


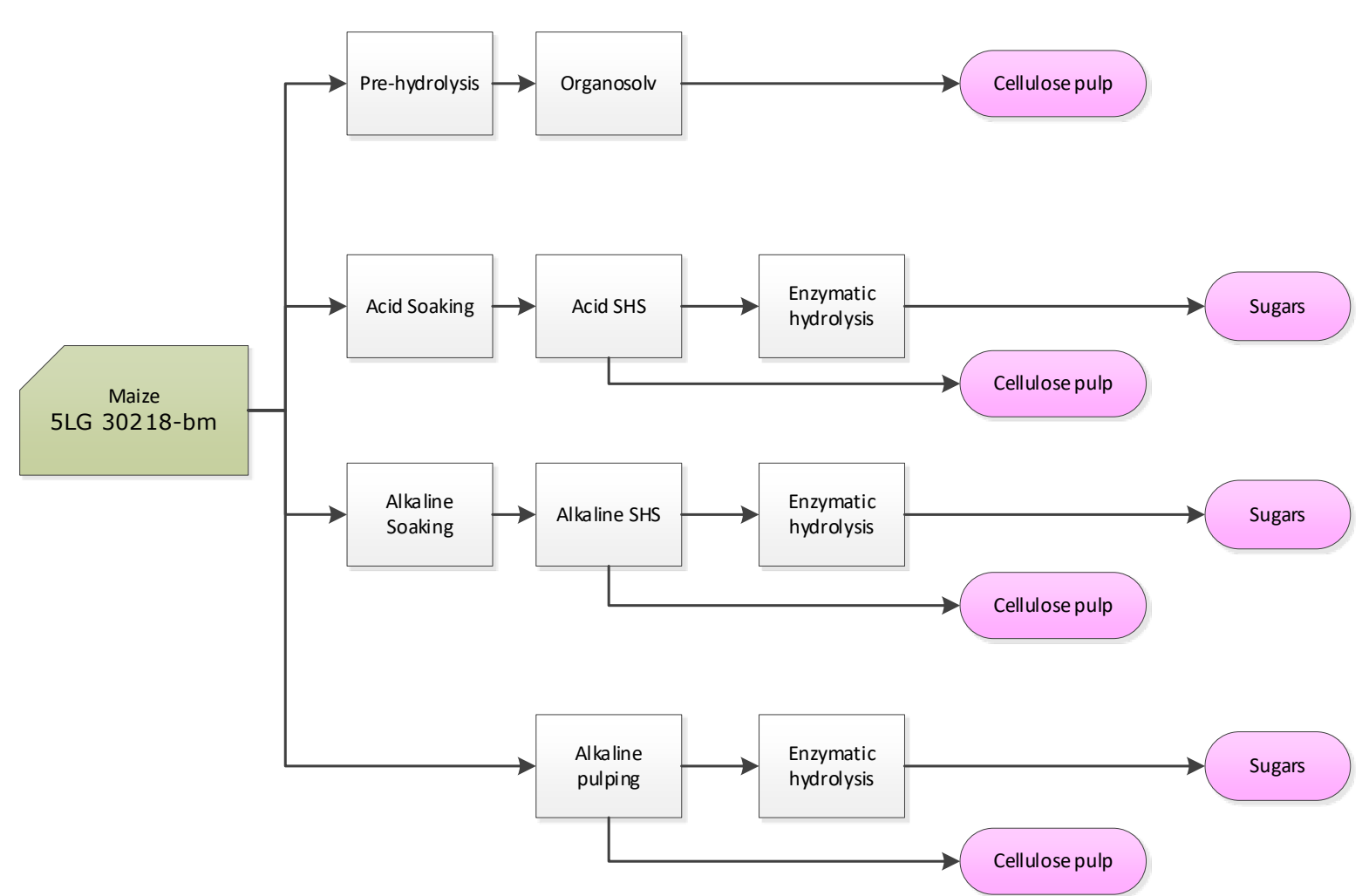

Figure 2 This study: four different pulping processes for enzymatic hydrolysis into fermentable sugars or to produce cellulose pulp

Figure 3 shows the role of $\mathrm{pH}$ in pretreatment processes in relation to changes in chemical composition of the lignocellulosic matrix. As a rule of thumb, one can say that at lower $\mathrm{pH}$ the hemicellulose fraction is dissolved leaving a solid fraction enriched in lignin and cellulose. On the other hand, under alkaline conditions or high $\mathrm{pH}$ more of the lignin fraction is dissolved, leaving a solid residue enriched in cellulose and hemicellulose (see Figure 3).



Figure 3 Changes in chemical composition solid fraction after pretreatment and relation to pH (Adapted from Carvalheiro et al (2008) Journal of Scientific and Industrial Research 67(11): 849-864)

In chapter 2 the materials and methods are described, in chapter 3 the results of the cellulose pulp production and hand sheets, and subsequently the enzymatic hydrolysis of all samples to monomeric sugars. This report is finalized with overall conclusions and recommendations in chapter 4. 


\section{Materials and methods}

\subsection{Materials}

- Three different maize genotypes (Ambrosini, 10LG 30248 and 5LG 30218-bm) of freshly harvested maize plants were supplied by WPR. The maize plants consisted of stems and leaves. The samples are illustrated in Figure 4.

- $\quad$ For the enzymatic treatment, Ctec 2 from Sigma Aldrich was used. To prevent bacterial growth Pen Strep originating from Penicillin Streptomycin was used, obtained by Sigma Aldrich.

- $\quad$ Other chemicals were obtained by VWR, Merck or Sigma.
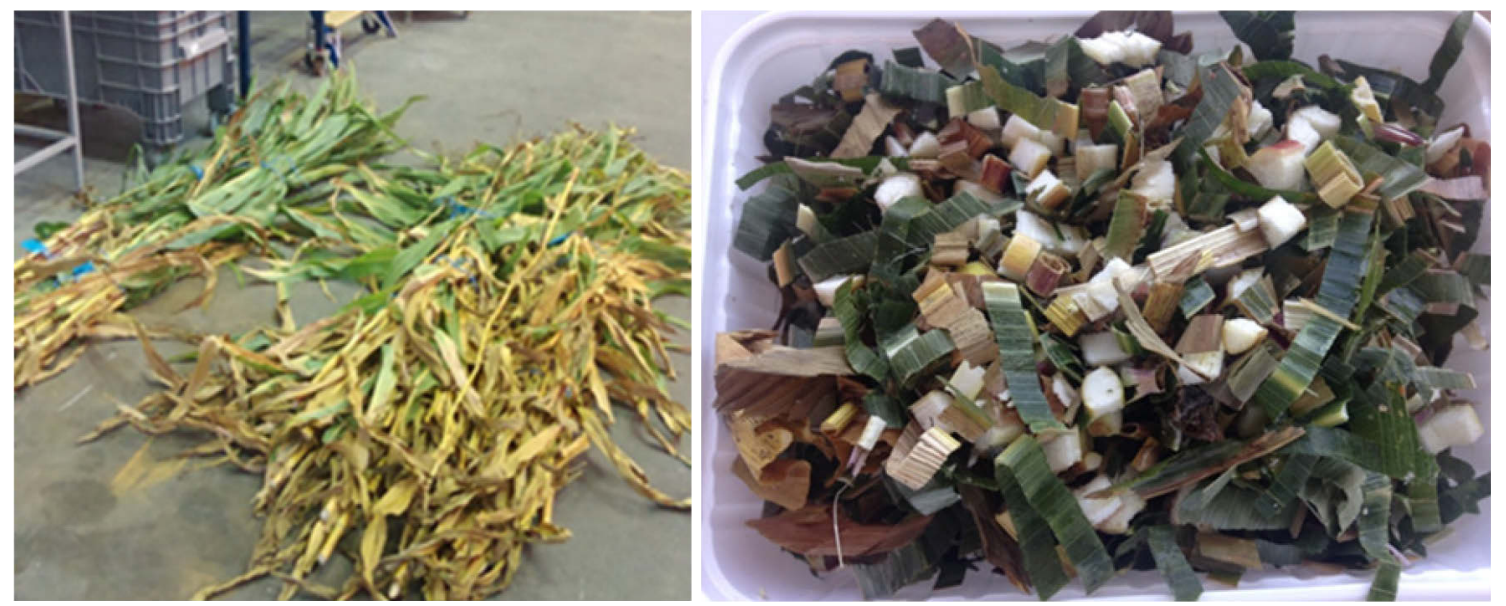

Figure 4 Freshly harvested maize plants (left), after cutting (right)

\subsection{Pretreatment methods}

Within one day after harvesting, maize plants (stem and leaves) were chopped into pieces of maximum $6.25 \mathrm{~mm}$ with a Pierret cutting machine. The materials were stored at $-20{ }^{\circ} \mathrm{C}$ prior to further treatment.

\subsubsection{Acid hydrolysis and enzymatic hydrolysis}

Maize was treated with sulphuric acid at 130 and $160{ }^{\circ} \mathrm{C} .4 .5 \mathrm{w} / \mathrm{w} \%$ biomass was dispersed in water in a stainless steel $100 \mathrm{~mL}$ reaction vessel. $2.2 \mathrm{w} / \mathrm{w} \% \mathrm{H}_{2} \mathrm{SO}_{4}$ on dry biomass was used to lower the $\mathrm{pH}$ between 1.5 and 2.0. The reaction was performed for 30 minutes at $160{ }^{\circ} \mathrm{C}$ without stirring. Heating was applied by submerging the reaction vessels in a preheated silicon oil bath. The temperature was measured using a thermocouple and Piotech data recorder Acid treatment started as the desired temperature in the reaction vessel had been achieved. After cooling the cellulose pulp and liquid fraction 1 were separated using a tea sieve.

For the enzymatic hydrolysis a $5 \mathrm{w} / \mathrm{w} \%$ dispersion in water was prepared in a closed vessel of $250 \mathrm{~mL}$. The $\mathrm{pH}$ was adjusted to $\mathrm{pH} 5$ with $2 \mathrm{~N} \mathrm{NaOH}$. The solution was stirred and heated up to $55^{\circ} \mathrm{C}$ in a water bath. A dose of $0.02 \mathrm{~mL} / \mathrm{g}$ dry biomass antibiotic Pen Strep (Penicillin Streptomycin) was added to prevent the hydrolysis mixture from undesired microbial conversion. The enzyme CTec2 ( $5 \mathrm{w} / \mathrm{w} \%)$ was added to start the reaction. After 24 and 72 hours the enzyme was inactivated at $90^{\circ} \mathrm{C}$ for 10 minutes. After cooling remaining solids were separated from the hydrolysis liquid by centrifugation (15 minutes, $15000 \times \mathrm{g}, 15^{\circ} \mathrm{C}$ ). The processing scheme is given in Figure 5 . 


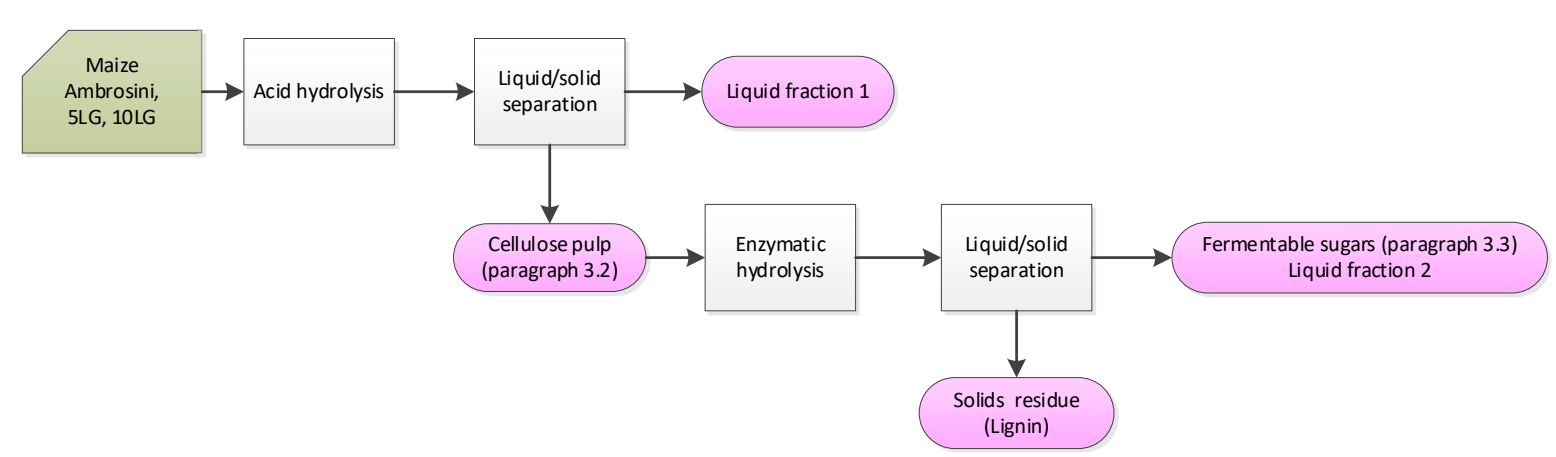

Figure 5 Acid hydrolysis followed by enzymatic hydrolysis to sugars

\subsubsection{Prehydrolysis with water and organosolv pulping}

Maize was first prehydrolysed (autohydrolysed) for 60 minutes at $170{ }^{\circ} \mathrm{C}$. Thereafter an organosolv process took place with $80 \%$ acetic acid as organic solvent at $170^{\circ} \mathrm{C}$ for 90 minutes. The samples were washed three times with acetic acid to remove solubilized lignin and three times with water, filtered and dried in the fume hood.

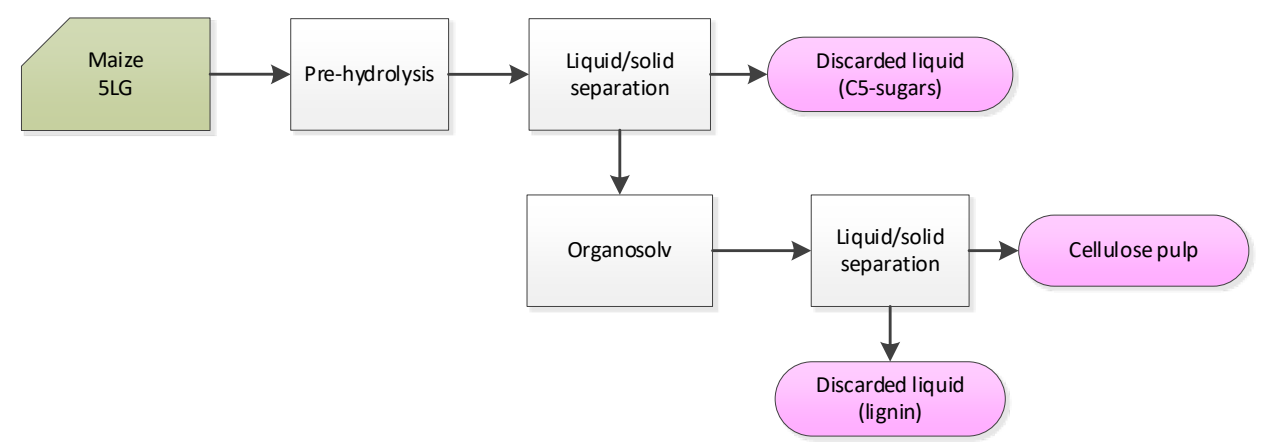

Figure 6 Prehydrolysis followed by organosolv pulping

\subsubsection{Acid soaking and superheated steam treatment}

$1 \mathrm{~kg}$ of dry maize was soaked (overnight) in $2 \% \mathrm{H}_{2} \mathrm{SO}_{4}$ solution, with a solid to liquid ratio of $1: 10$. After draining over a cheese cloth the material was treated in the SHS reactor for 10 minutes at $160{ }^{\circ} \mathrm{C}$ and 6 bar. The solid material was washed 4-5 times with water and solids were separated from the liquid with a cheese cloth. For analysis purposes, the material was stored in the freezer at $-20^{\circ} \mathrm{C}$.

Enzymatic hydrolysis was done as described in paragraph 2.2.1.

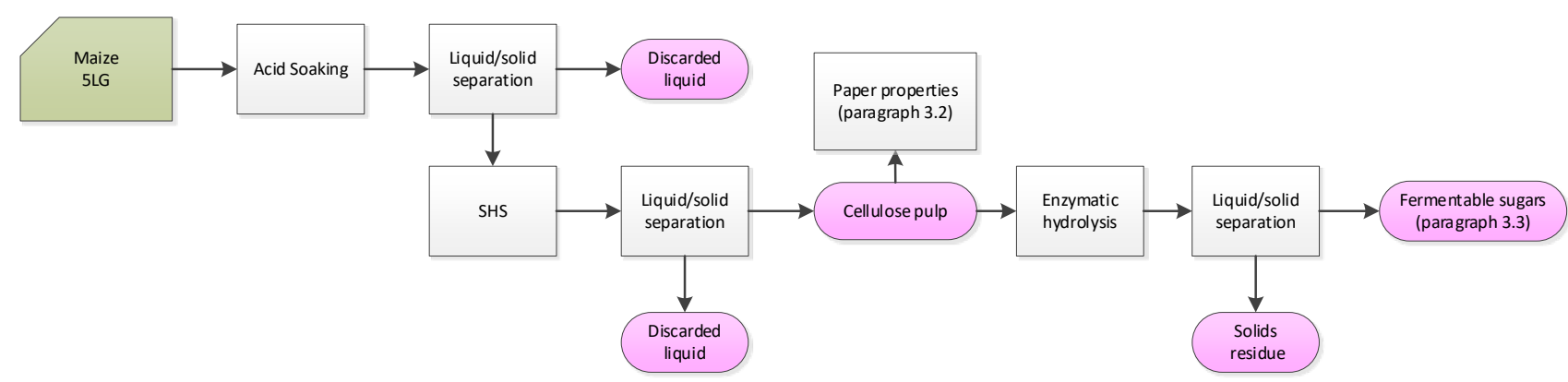

Figure 7 Acid soaking followed by superheated steam (SHS) treatment

\subsubsection{Alkaline soaking and superheated steam treatment}

$1 \mathrm{~kg}$ of dry maize was soaked (overnight) in water with $15 \% \mathrm{NaOH}$ based on the dry material, with a solid to liquid ratio of $1: 10$. After draining over a cheese cloth the material was treated in the SHS reactor for 10 minutes at $160^{\circ} \mathrm{C}$ and 6 bar. The solid material was washed $4-5$ times with water and 
solids were separated from the liquid phase by a cheese cloth. For analysis purposes, the material was stored in the freezer at $-20^{\circ} \mathrm{C}$.

Enzymatic hydrolysis was done as described in paragraph 2.2.1.

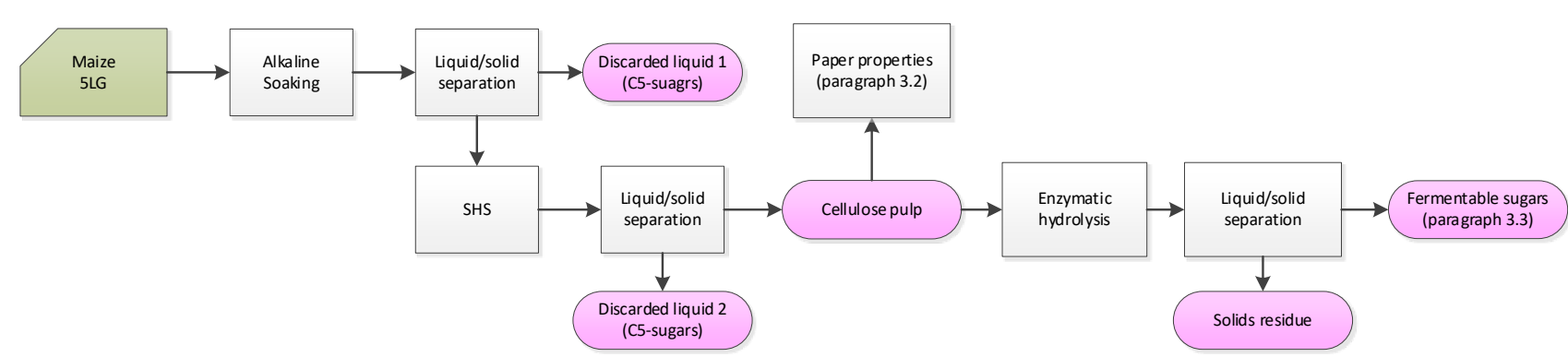

Figure 8 Alkaline soaking followed by superheated steam (SHS) treatment

\subsubsection{Alkaline pulping in 50L conical screw reactor}

An alkaline extraction in a conical $50 \mathrm{~L}$ reactor was performed on the genotype $5 \mathrm{LG}$. Approximately $1-2 \mathrm{~kg}$ of dry material was placed into the $50 \mathrm{~L}$ reactor. Water was added in the solid to liquid ratio of $1: 10$ and $15 \mathrm{w} / \mathrm{w} \% \mathrm{NaOH}$ based on the dry matter was added to the mixture. The extraction was carried out for $90 \mathrm{~min}$. at $120^{\circ} \mathrm{C}$.

After the extraction, the mixture was poured over a cheese cloth to separate the liquid fraction. The solid material was washed for 5-6 times with water and the liquid and solid fractions were separated with a cheese cloth. For analysis purposes, the material was stored in the freezer at $-20^{\circ} \mathrm{C}$.

Enzymatic hydrolysis was done as described in paragraph 2.2.1.

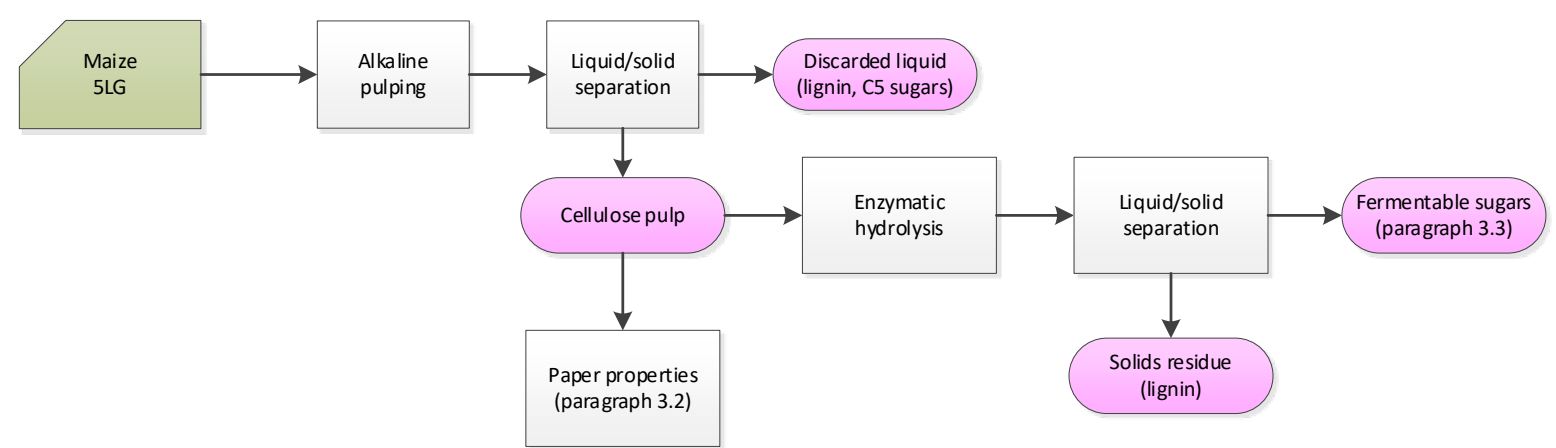

Figure 9 Alkaline pulping in conical screw reactor

\subsection{Analysis methods}

\subsubsection{Chemical composition maize biomass}

Sample material was dried at $50^{\circ} \mathrm{C}$ and milled. The samples were hydrolysed with sulphuric acid (12M 1 hour at $30^{\circ} \mathrm{C}, 1 \mathrm{~N} 3$ hours at $100^{\circ} \mathrm{C}$ ). The formed monosaccharides in the hydrolysate were quantified by HPAEC (Dionex Corporation, California, USA). The acid insoluble lignin was determined gravimetrically after washing and the acid soluble lignin in the hydrolysate was determined spectrophotometrically at $205 \mathrm{~nm}$ (TAPPI UM 250). Uronic acids in the hydrolysate were also determined spectrophotometrically according to the method described by Blumenkrantz. 


\subsubsection{Enzymatic kits for glucose and xylose}

To determine the concentration of glucose and xylose, enzymatic kits of Megazyme were used:

- The D-Glucose kit is a UV-method (measurement at $340 \mathrm{~nm}$ ) for the determination of D-glucose in foodstuffs, beverages and other materials.

- The D-Xylose kit is a UV-method (measurement at $340 \mathrm{~nm}$ ) for the determination of D-xylose in fermentation broths and hydrolysates of plant material and polysaccharides.

\subsubsection{Fibre properties}

The wet cellulose pulp was disintegrated using a valley beater according to ISO 5264/1 (360 g pulp is required). Instead of 360 grams, an equivalent of 200 grams of oven-dried pulp was used. After disintegration a small sample was taken, and the beating degree was measured according to ISO 5267-1 using the Schopper -Riegler apparatus. Subsequently laboratory beating of the pulp in the valley beater was performed to obtain a sample of about 30 and about 50 SR (Schopper-Riegler) beating degree. Beating degree as function of beating time was recorded.

Pulp samples taken at 30 and 50 SR beating degree were used to produce hand sheets according to ISO 5269/2 using the Rapid-Köthen sheet former. After conditioning for over 24 hours the mechanical properties of the sheets were measured: grammage (ISO 536), thickness (single sheet) and bulk (ISO 534), tensile properties (ISO 1924-2), tearing resistance (ISO 1974), SCT index (ISO 9895), air-permeance (ISO 5636) and roughness (ISO 8791). 


\section{Results and discussion}

\subsection{Chemical composition of maize biomass}

After harvesting and cutting of the maize plants an inhomogeneous mixture of stems and leaves was obtained. Homogeneous samples for analysis purposes were prepared by mixing stems and leaves and milling it to a fine powder, and these samples were used to determine the chemical composition.

The results of the chemical composition of the three different maize genotypes are shown in Table 1 . Compared to other lignocellulosic biomasses these samples contained a high amount of water-soluble extractives, most likely due to soluble sugars that are present in the stems. Ambrosini contained the highest amount of lignin, 5LG sample the lowest.

Table 1 Chemical composition of the maize starting materials: Ambrosini, 10LG and 5LG.

\begin{tabular}{l|ccc|cccccc|c|c|c|c}
\hline & \multicolumn{3}{|c|}{ Extractives } & \multicolumn{4}{c|}{ Average polysaccharide contents } & \multicolumn{3}{c|}{ Lignin } & Total \\
\hline & $\begin{array}{c}\text { ethanol/ } \\
\text { toluene } \\
(\%)\end{array}$ & $\begin{array}{c}\text { ethanol } \\
(\%)\end{array}$ & $\begin{array}{c}\text { water } \\
(\%)\end{array}$ & $\begin{array}{c}\text { Arabinose } \\
(\%)\end{array}$ & $\begin{array}{c}\text { Xylose } \\
(\%)\end{array}$ & $\begin{array}{c}\text { Mannose } \\
(\%)\end{array}$ & $\begin{array}{c}\text { Galactose } \\
(\%)\end{array}$ & $\begin{array}{c}\text { Glucose } \\
(\%)\end{array}$ & $\begin{array}{c}\text { Rhamnose } \\
(\%)\end{array}$ & $\begin{array}{c}\text { Uronic } \\
\text { acids } \\
(\%)\end{array}$ & $\begin{array}{c}\text { AIL } \\
(\%)\end{array}$ & $\begin{array}{c}\text { ASL } \\
(\%)\end{array}$ & $\begin{array}{c}\text { (\%) } \\
(\%)\end{array}$ \\
\hline Ambrosini & 8.02 & 2.78 & 12.31 & 2.28 & 14.80 & 0.25 & 0.78 & 27.53 & 0.11 & 1.01 & 13.07 & 1.61 & 84.54 \\
10LG 30248 & 10.22 & 3.77 & 11.96 & 2.21 & 14.54 & 0.19 & 0.65 & 26.88 & 0.09 & 1.23 & 10.77 & 1.77 & 84.30 \\
5LG 30218-bm & 4.77 & 1.40 & 13.94 & 2.85 & 16.34 & 0.27 & 0.80 & 29.83 & 0.14 & 1.36 & 9.12 & 1.88 & 82.69 \\
\hline \hline
\end{tabular}

\subsection{Cellulose pulp from maize stems and leaves}

\subsubsection{Introduction}

Aim of this part of the study was to produce a cellulose pulp from maize biomass by four different pulping processes. The following treatments were applied on one maize genotype (5LG 30218-bm):

1. Pre-hydrolysis at $170^{\circ} \mathrm{C}$, followed by an organosolv treatment with $80 \%$ acetic acid at $170^{\circ} \mathrm{C}$

2. Acid soaking and SHS (Superheated Steam)

3. Alkaline soaking and SHS (Superheated Steam)

4. Alkaline pulping for 90 minutes at $120^{\circ} \mathrm{C}$

The first experiment was based on the patent EP2556190 A1 entitled "Acetic acid based refining process of biomass". The process is a combination of a pre-hydrolysis step in water at high temperature $\left(150-170^{\circ} \mathrm{C}\right)$, followed by a hydrolysis with $80 \%$ acetic acid at $170^{\circ} \mathrm{C}$ for 90 minutes.

The second treatment and third treatment included a treatment with the Superheated steam equipment at TNO in Zeist (Figure 10, left picture). Before the SHS treatment the material was soaked overnight in acid or in alkaline solutions.

The last treatment was an alkaline treatment for 90 minutes at a temperature of $120^{\circ} \mathrm{C}$ in a $50 \mathrm{~L}$ stirred reactor (Figure 10, right picture). 


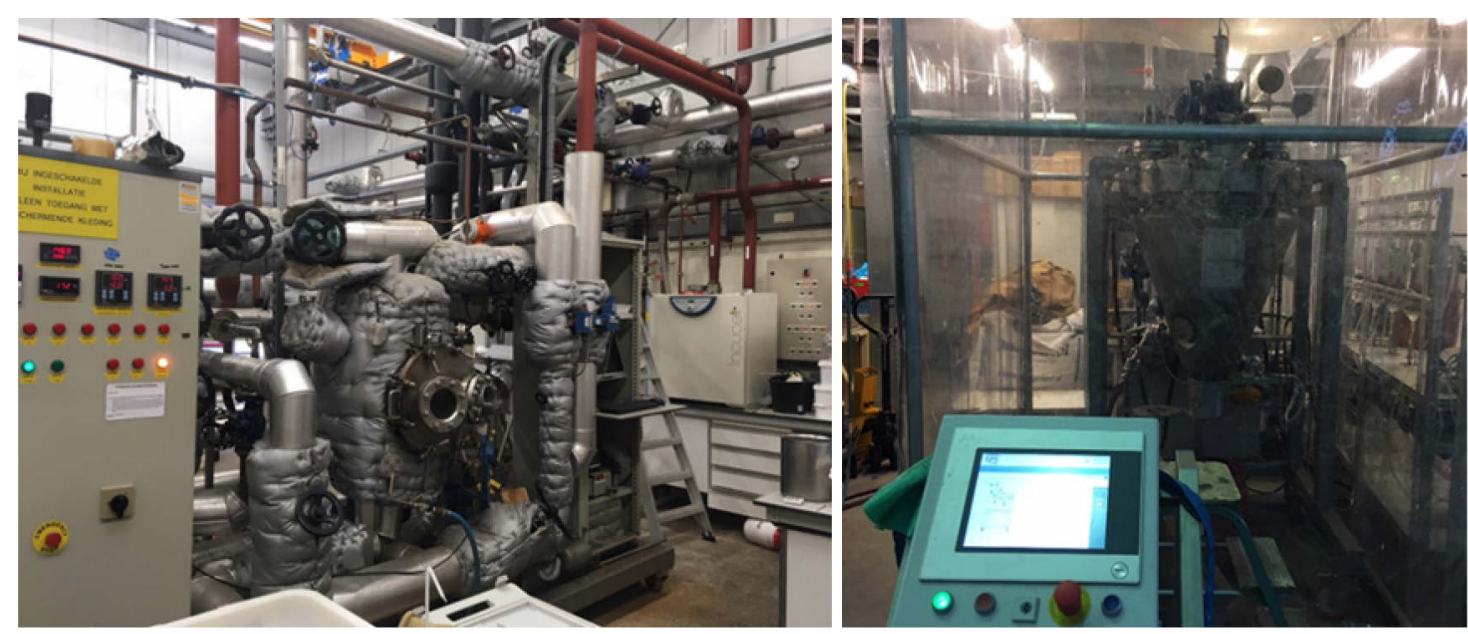

Figure 10 SHS equipment (left picture) and conical screw reactor used for alkaline pulping (right picture)

\subsection{2 $\mathrm{pH}$ during treatment}

The $\mathrm{pH}$ of the liquid phases was determined during processing (Table 2). Large differences were observed, even after washing of the samples.

Table 2 pH of the liquid phases and the washed pulp.

\begin{tabular}{llccc} 
Sample & & pH during soaking & pH after treatment & pH of pulp after \\
waize $5 L G$ & Organosolv & n.d. & n.d. & n.d. \\
\hline Maize $5 L G$ & Acid SHS & 1.2 & 2.0 & 3.7 \\
Maize $5 L G$ & Alkaline SHS & 12.6 & 10.5 & 9.5 \\
\hline Maize $5 L G$ & Alkaline $120^{\circ} \mathrm{C}$ & n.a. & 12.2 & 10.4 \\
\hline
\end{tabular}

\subsubsection{Pulping yield}

Table 3 shows the results of the yield of the total dry matter of the solid fraction after treatment and a picture of the obtained material. The organosolv and acid-SHS treatments resulted in a more fibrous material, whereas after the alkaline treatments the samples were more similar to a cellulose pulp. The alkaline pulp had the highest yield of dry matter. This was unexpected, as in general alkaline pulping results in lower dry matter yields compared to acid-processes. The organosolv material was not used for further analysis due to the high fibrous appearance of the sample. 


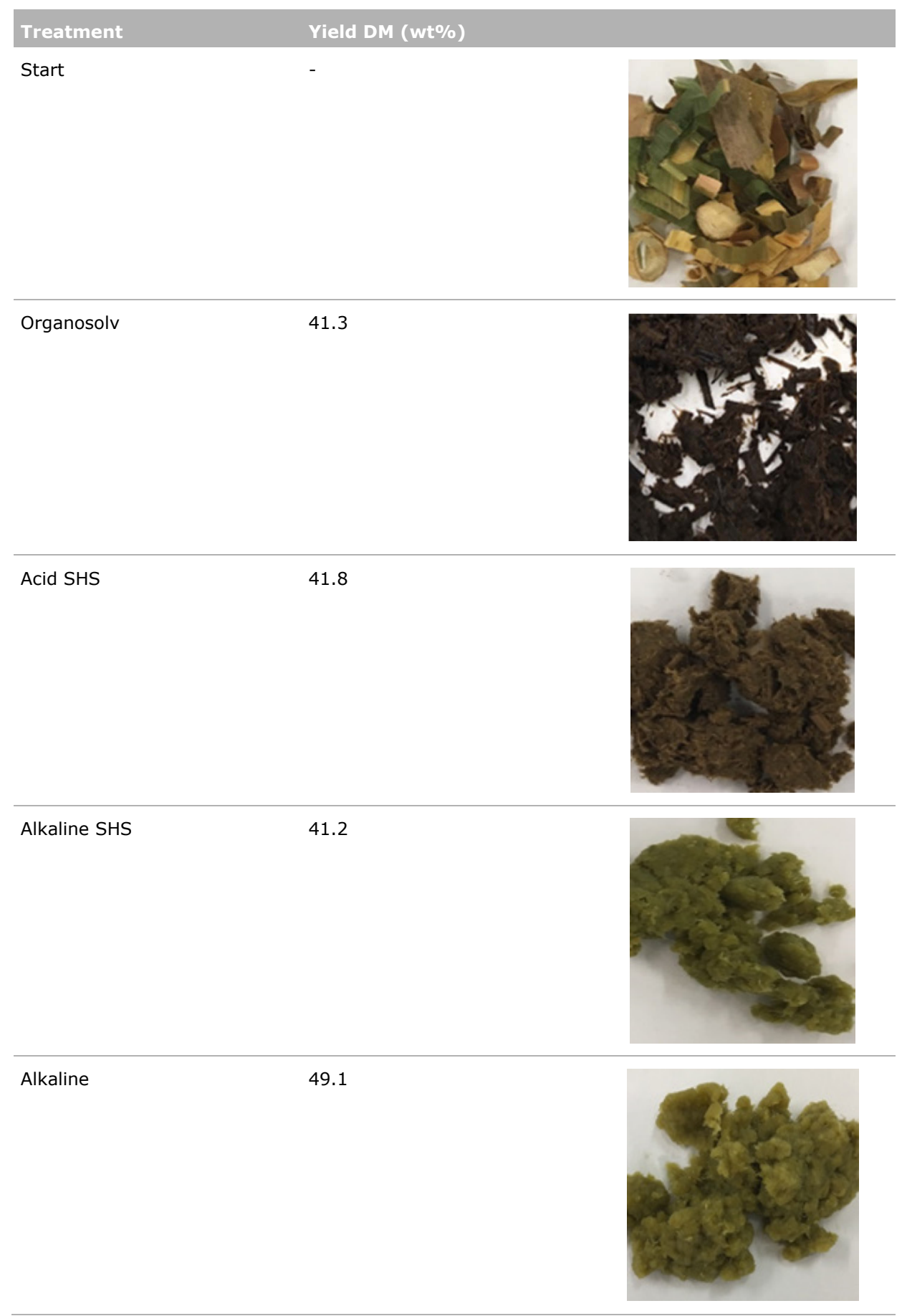

\subsubsection{Chemical composition after treatment}

The chemical composition of the solid fractions after the various pulping processes is shown in Figure 11. The liquid fractions were not analysed for their composition, and for the solid fractions the amount of extractives was also not measured as it was assumed that due to processing the extractives were already removed from the solid parts.

The glucose content (cellulose) after treatment was increased from $30 \%$ to $65 \%$ for acid-SHS treatment and from $30 \%$ to $58 \%$ for the alkaline-(SHS) treatment. After acid SHS treatment still a high percentage of lignin (AIL) was present in the product. After the alkaline treatments a high amount of xylose (hemicellulose) was still present.

In general, more purification steps are required to obtain a pure cellulose product from these samples. 


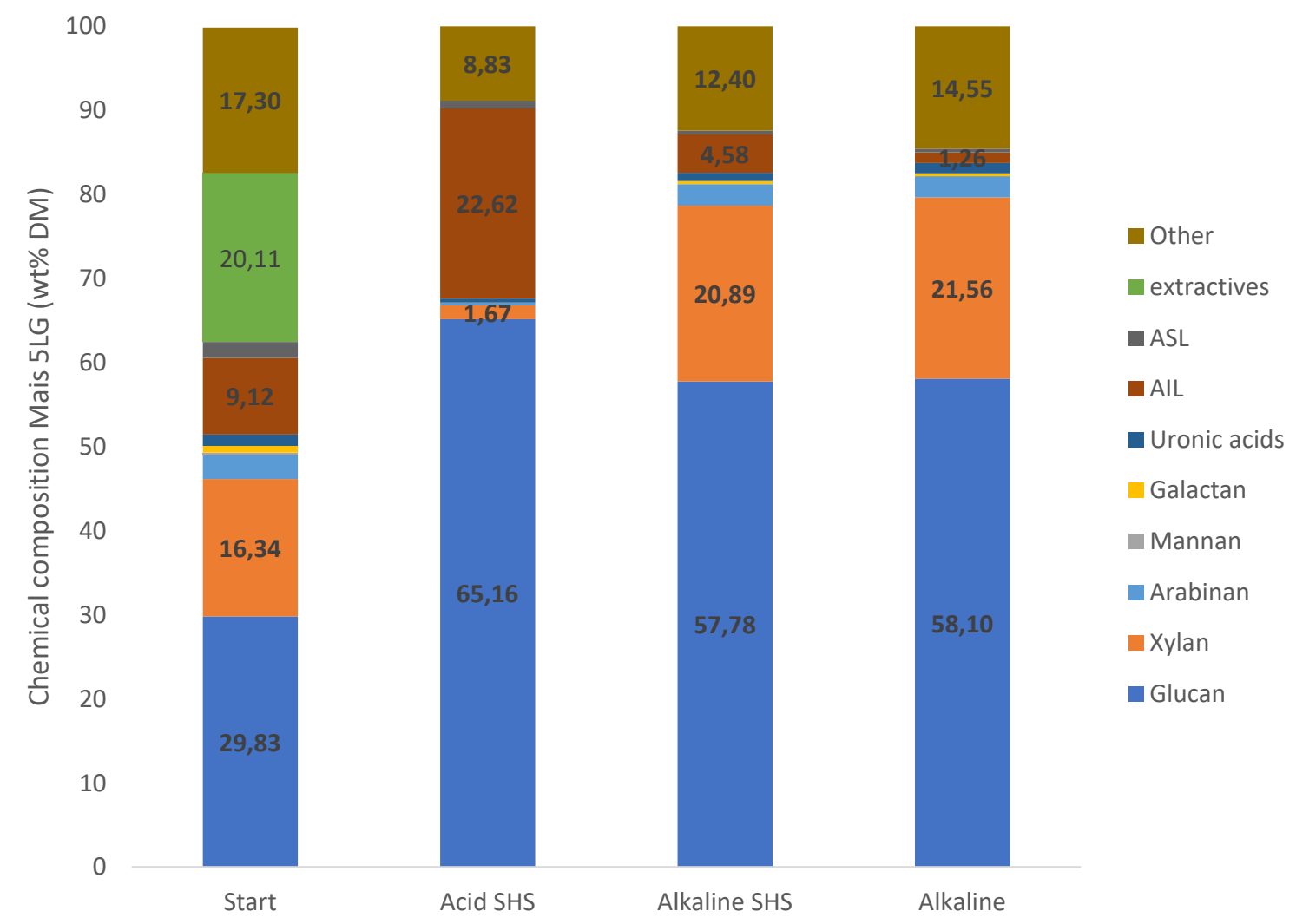

Figure 11 Chemical composition of the cellulose pulps made from the maize genotype 5LG after treatment

\subsubsection{Mass balances}

By combining dry matter yields and chemical composition of the solid fractions, mass balances can be created, providing more information on the degree of delignification and dissolution/retention of cellulose and hemicellulose. For maize 5LG this is illustrated in Figure 12. The numbers highlighted in green are the corresponding yields of glucan, xylan and lignin (AIL). A compilation of the data is shown in Table 4.

Table 4 Compilation of mass balances. Composition in $\mathrm{g} / 100 \mathrm{~g} D \mathrm{M}$, yield of the corresponding components in brackets in $w / w \% D M$.

\begin{tabular}{ccccc} 
Component & $\begin{array}{c}\text { Composition } \\
(\mathrm{g} / 100 \mathrm{~g} \text { DM })\end{array}$ & $\begin{array}{c}\text { Composition } \\
(\mathrm{g} / 100 \mathrm{~g} \text { DM })\end{array}$ & $\begin{array}{c}\text { Composition } \\
(\mathrm{g} / 100 \mathrm{~g} \mathrm{DM})\end{array}$ & $\begin{array}{c}\text { Composition } \\
(\mathrm{g} / 100 \mathrm{~g} \text { DM })\end{array}$ \\
\hline Maize $5 \mathrm{LG}$ & Acid SHS & Alkaline SHS & Alkaline \\
\hline Klucan & 30 & $27(91 \%)$ & $24(81 \%)$ & $24(81 \%)$ \\
\hline Lylan & 16 & $1(4 \%)$ & $9(53 \%)$ & $9(55 \%)$ \\
\hline
\end{tabular}

Table 4 shows that retention of cellulose in the samples was the highest for the acid SHS treatment $(91 \%)$, but also the alkaline treatments resulted in a high retention of cellulose $(81 \%)$. For removal of hemicellulose the acid SHS treatment is by far the most efficient one. Under these conditions, only $4 \%$ of the hemicellulose remains in the sample and more than $90 \%$ is removed by the treatment. For further research the composition of the liquid fraction will be analysed to see whether C5 sugars are dissolved or further degradation to furfural and organic acids has occurred. For removal of lignin the alkaline processes are preferred, as in the acid SHS process no lignin was removed. 


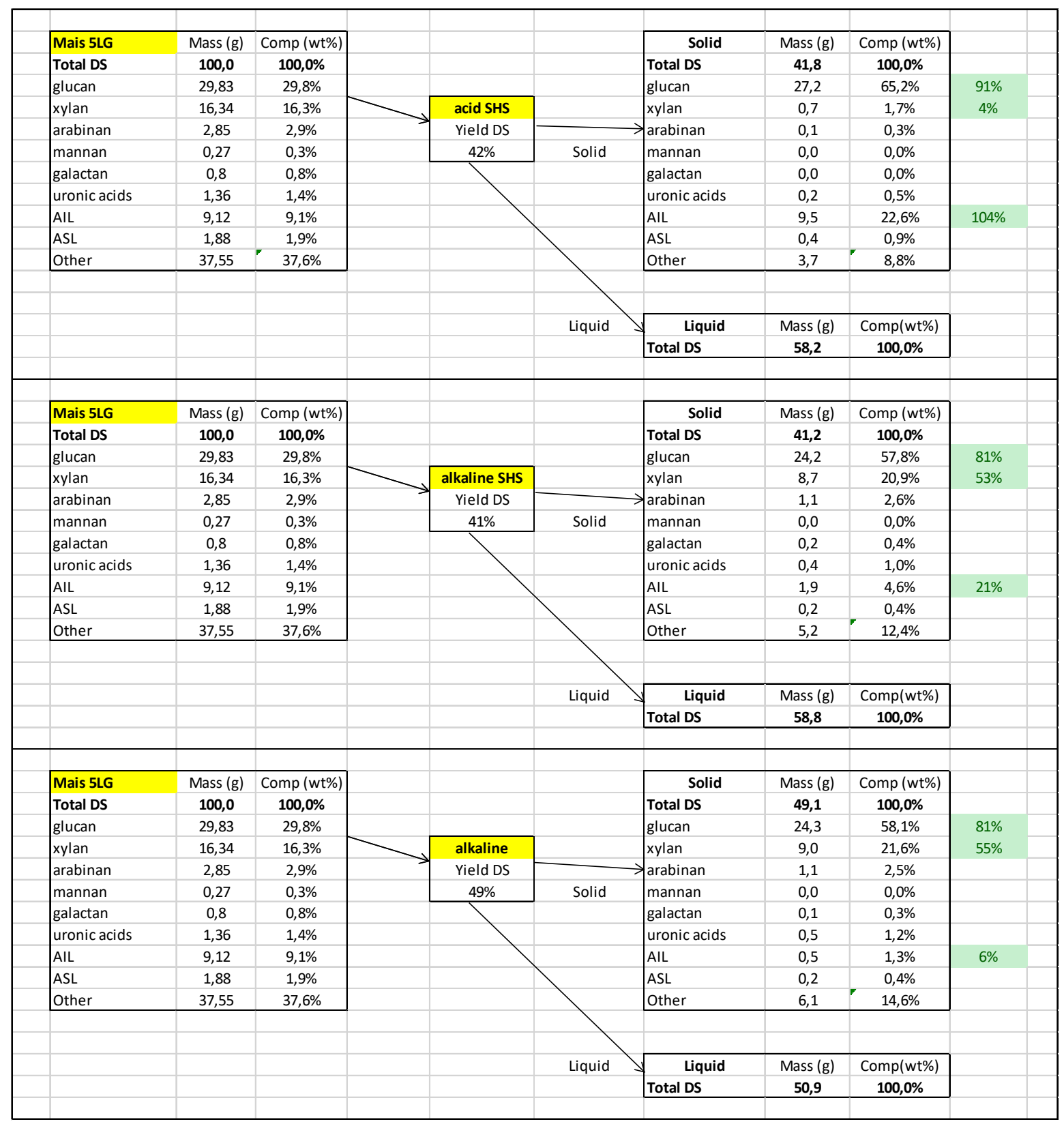

Figure 12 Mass balances for processing of maize (genotype 5LG) to cellulose pulp. Highlighted in green are the yields for glucan, xylan and lignin 


\subsubsection{Fibre properties of cellulose pulps}

In this study we compared different options for the production of a cellulose pulp from maize stems and leaves. This cellulose pulp can be further purified to dissolving cellulose but can also be used as unbleached pulp for the paper industry. The fibre properties of the cellulose pulp were tested in this study.

To evaluate the differences, the pulps were disintegrated (to remove entanglements between fibres/fibre bundles) and consequently mechanically beaten to free the fibres from the remaining fibrebundles and to fibrillate the fibres. The mechanical properties of the hand sheets made from these pulps at specific beating degrees (30 and 50 SR) provides insight in the morphology of the pulps after the chemical treatments and on the performance of these pulps for the application in paper products.

The beating degree of a cellulose pulp is an index to reflect water filtration degree. In general, the higher the beating degree, the lower the filtration speed. The beating degree of an unbeaten commercial chemical pulp is well below $20 \mathrm{SR}$, as beating (which is required to get fibres suitable for paper making) will result in an increase in beating degree.

The beating degree of all three unbeaten pulps of this project was above 20 SR (Figure 13). This could be due to fine particles present in the pulp. The pulp produced with alkaline pretreatment and superheated steam was above $30 \mathrm{SR}$. The beating degree was only slowly increasing for the acid treated pulp during beating in comparison with the alkaline treated pulps.

Additional washing stages to remove fines would be necessary for optimal use of maize pulp in the paper industry (resulting in a lower pulp yield).

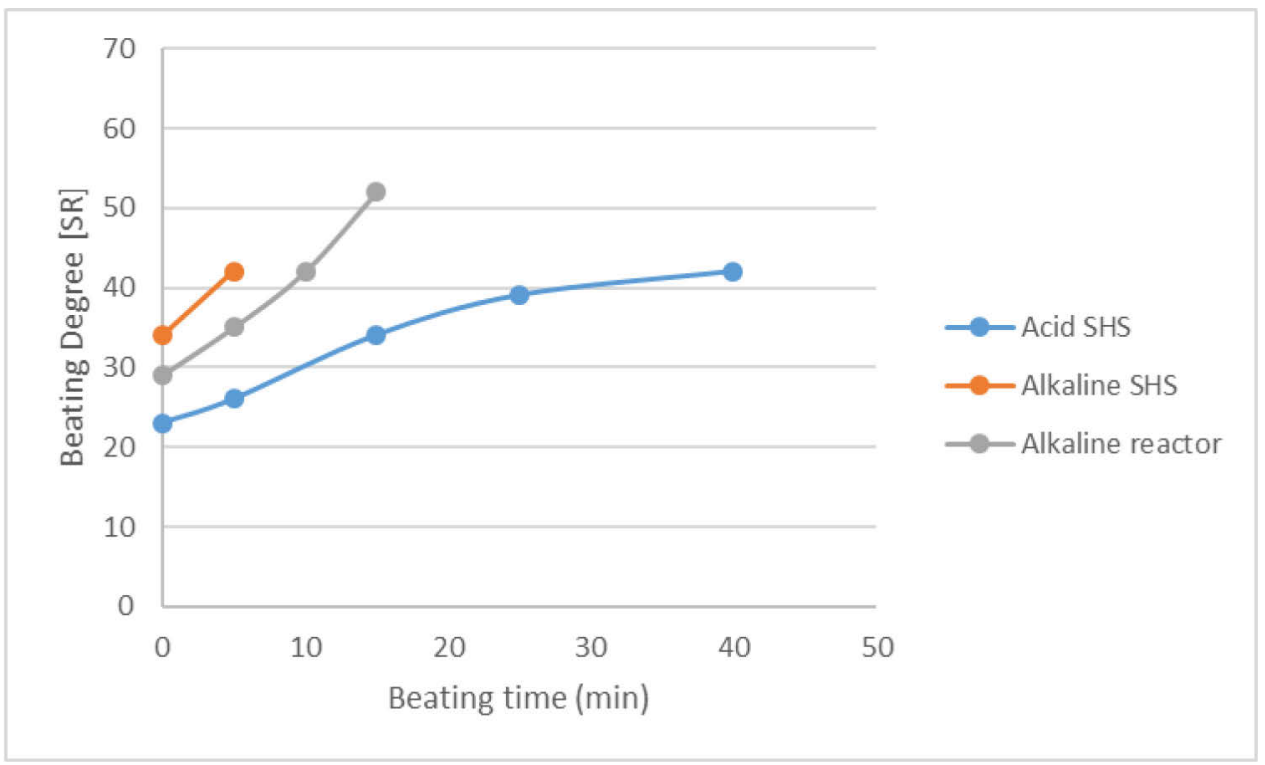

Figure 13 Beating degree as function of beating time

\subsubsection{Mechanical properties of hand sheets}

The bulk (reciprocal density) of prepared hand sheets shows whether the pulp consists of single fibres or larger particles or fibre bundles. Bulk diminishes upon increased beating. Bulk of the hand sheets as function of beating degree is shown in Figure 14. For chemical pulps of hard and softwood a bulk between 1 and $1.5 \mathrm{~cm}^{3} / \mathrm{g}$ is normally achieved. 


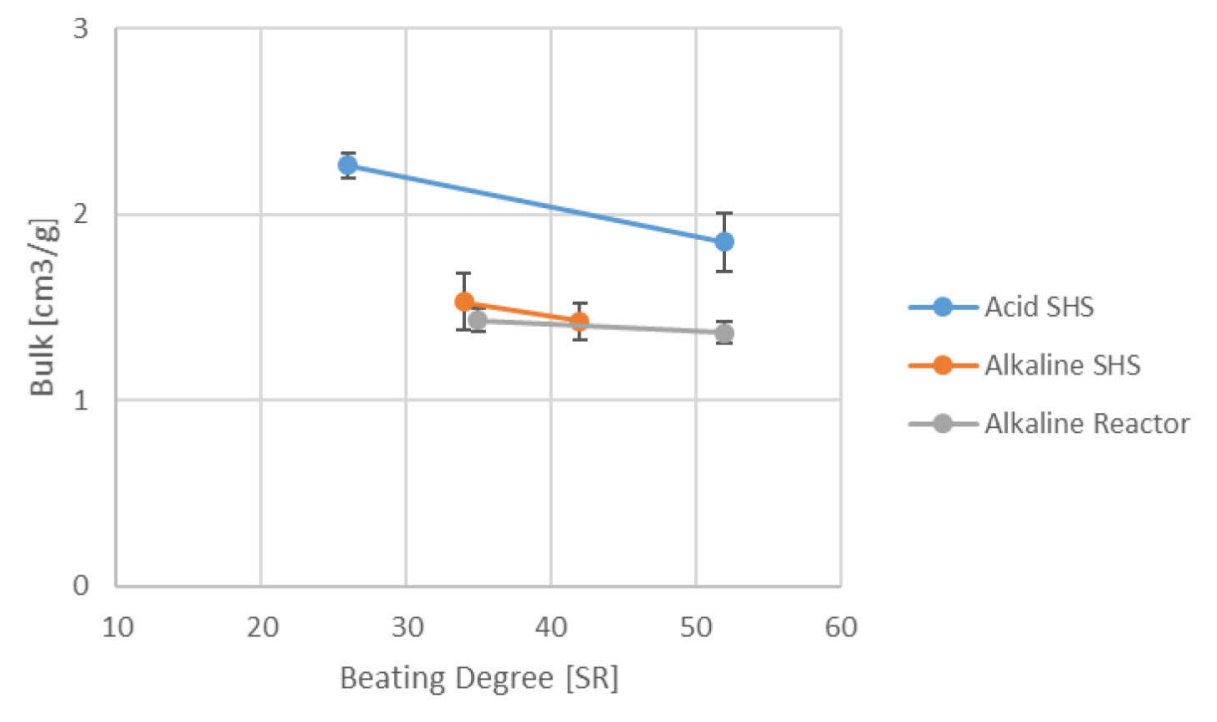

Figure 14 Bulk as function of beating degree after different pulping treatments

The acid treatment was less effective in breaking down the fibre bundles into fibres compared to the alkaline treatments. The acid treated maize pulp was not yet fully disintegrated into fibres, resulting in a high bulk value. The measured bulk levels of the alkaline treated pulps are at the higher side of chemical wood pulps. Apparently, the used pulping treatments were less severe than the chemical pulping treatments of commercial pulps.

\subsubsection{Physical properties of hand sheets}

The measurements of surface roughness and porosity of the produced hand sheets (see appendix 1) also showed that pulping of the maize samples resulted in larger particles and fibre bundles compared to commercial chemical pulps. Both values were outside the range of chemical pulps. The SCT strength and tear strength also showed that the cellulose pulp properties were in between mechanical and chemical pulps.

The tensile strength properties of the maize pulps are presented in Figure 15. The alkaline treated pulps had far higher tensile strength (represented here by breaking length) compared to the acid treated pulps. Tensile strength of the acid treated pulps was below recycled paper (mixed waste) quality. The acid treatment did not result in a pulp acceptable for paper production, except as filler or for decoration purposes. Tensile strength of the alkaline treated pulps was high compared to recycled paper, but below the tensile strength of hard- and softwood chemical pulps. Previous results with alkaline pulping of grass also resulted in higher tensile strength. 


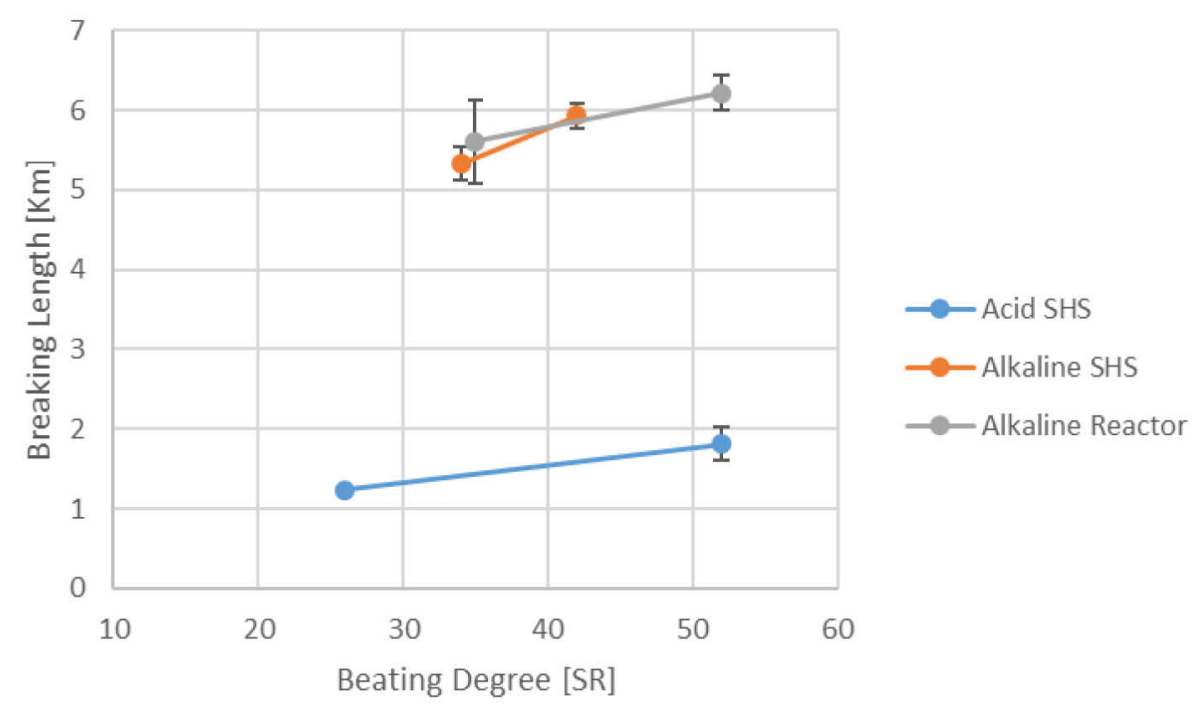

Figure 15 Breaking length of the produced hand sheets as function of beating degree

\subsubsection{Value for pulp production}

The properties of the pulps from maize stems and leaves were compared to existing wood pulps (obtained from commercial processes) and pulps made from grass from nature (own data).

In Figure 16 the tensile index (representing the tensile strength) of the different pulps is compared. As can be seen the tensile strength of the produced maize pulps is low compared to commercial chemical pulps and to chemical pulps made from grass.

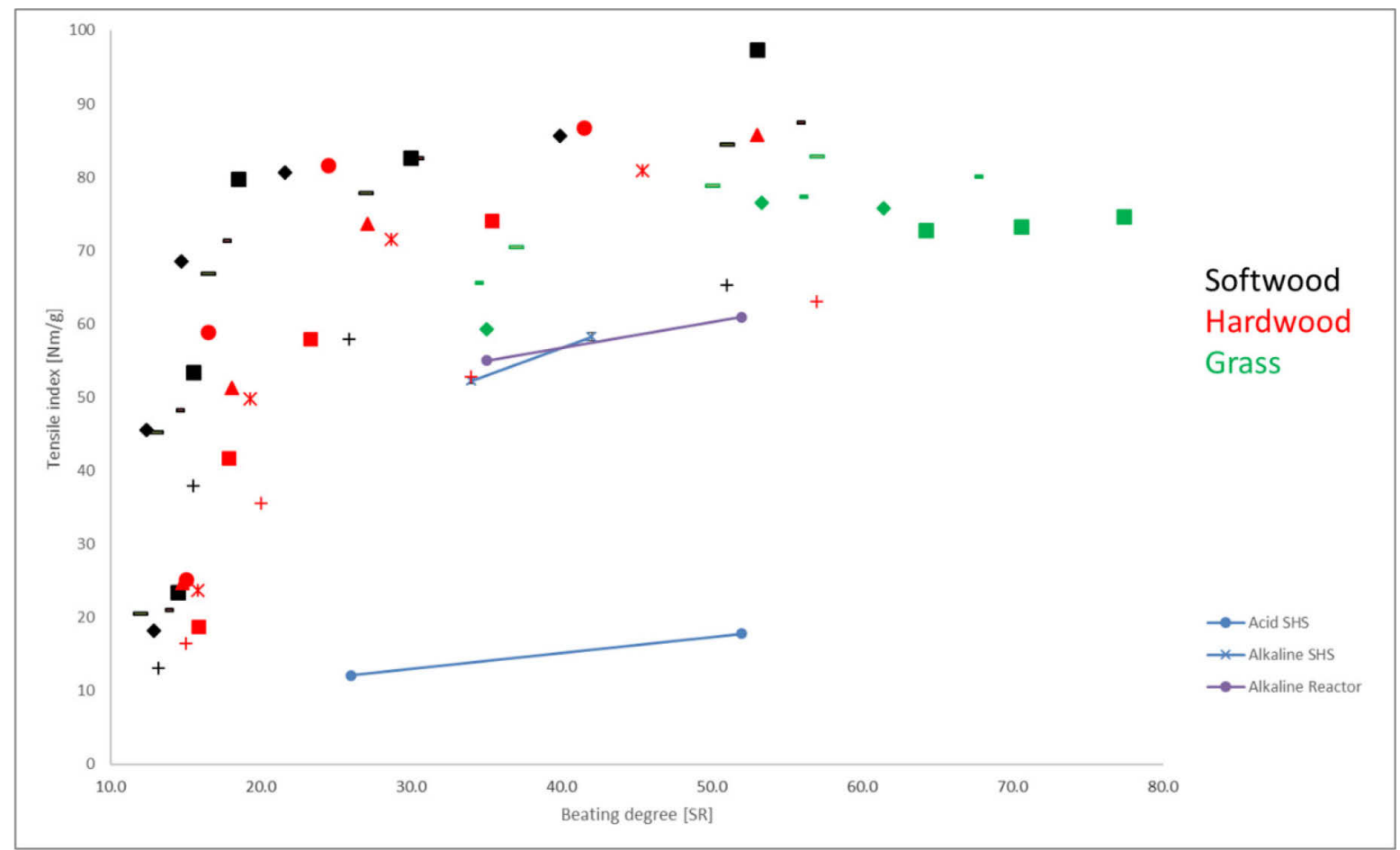

Figure 16 Tensile index of cellulose pulp from maize stems and leaves compared to commercial chemical pulps from softwood and hardwood and compared to pulp from grass 


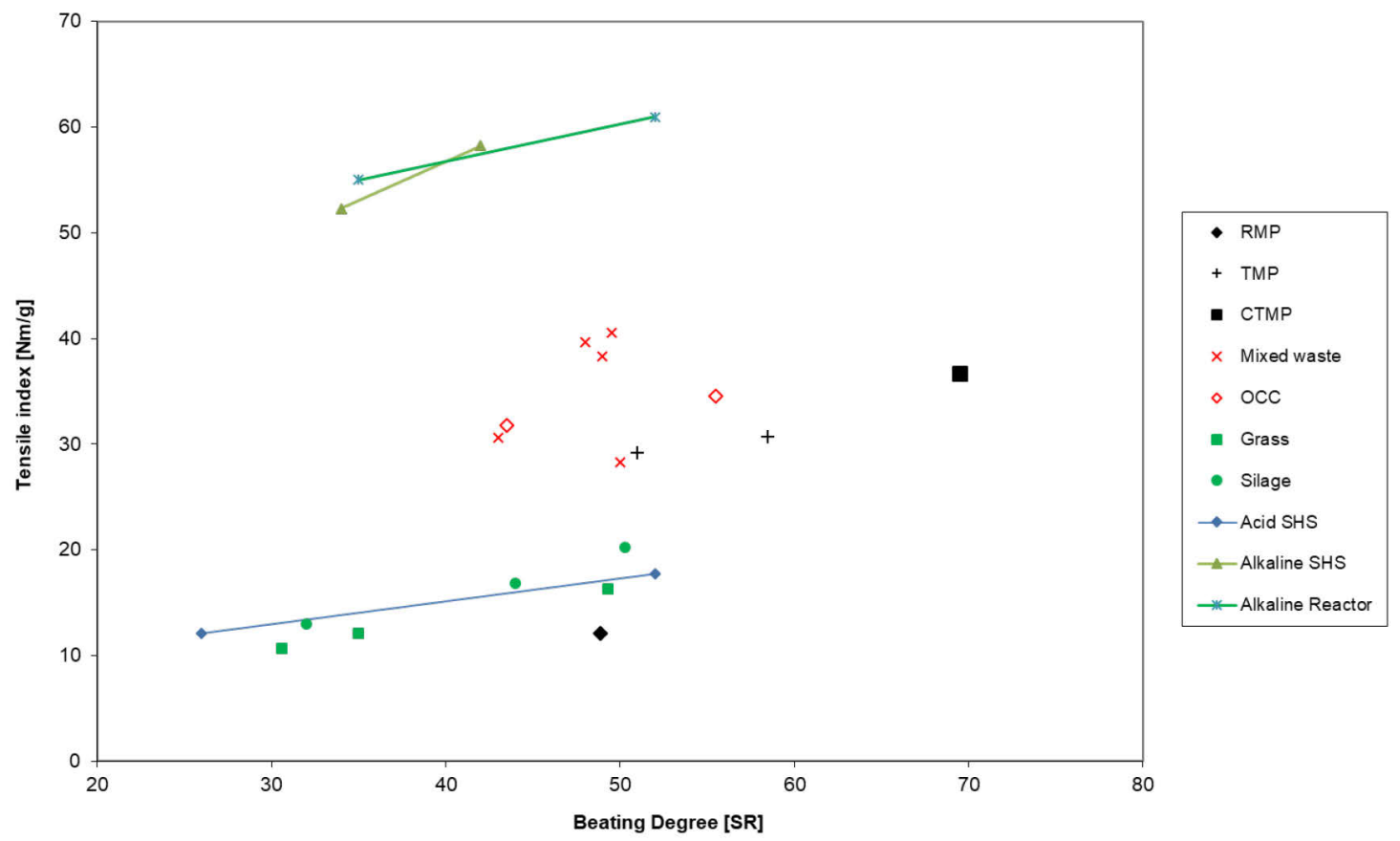

Figure 17 Tensile index of maize pulps compared to commercial (chemi-) mechanical pulps and recycled pulps. RMP=refined mechanical pulp, TMP=thermo mechanical pulp. CTMP=chemo thermo mechanical pulp, OCC=old corrugated containers

The tensile index of the produced maize pulps using alkali is higher than the strength of recycled paper, (chemi-)mechanical wood-based pulps and mechanically produced pulps from grass. The acid SHS pulp of maize is comparable with mechanically pulped grass. 


\subsection{Fermentable sugars from maize stems and leaves}

\subsubsection{Introduction}

In this paragraph the production of fermentable sugars from maize samples is described. In paragraph 3.3.2 the production of sugars from all three genotypes is described, where an acid pretreatment was done followed by an enzymatic hydrolysis. In paragraph 3.3.3 only the 5LG sample was used for the acid SHS, alkaline SHS and alkaline treatment, followed by enzymatic hydrolysis to produce the sugars.

\subsubsection{Enzymatic hydrolysis of acid hydrolysed samples}

The three maize genotypes were tested as feedstock to produce fermentable sugars. An acid pretreatment at 130 or $160^{\circ} \mathrm{C}$ was done to reduce the recalcitrance of the lignocellulose to enzymatic degradation. Additional heat treatment prior to acid treatment was assessed as a method to remove soluble stem storage sugars. Subsequently an enzymatic hydrolysis was performed to produce fermentable sugars. Figure 15 and Figure 16 show the samples before and after enzymatic hydrolysis.

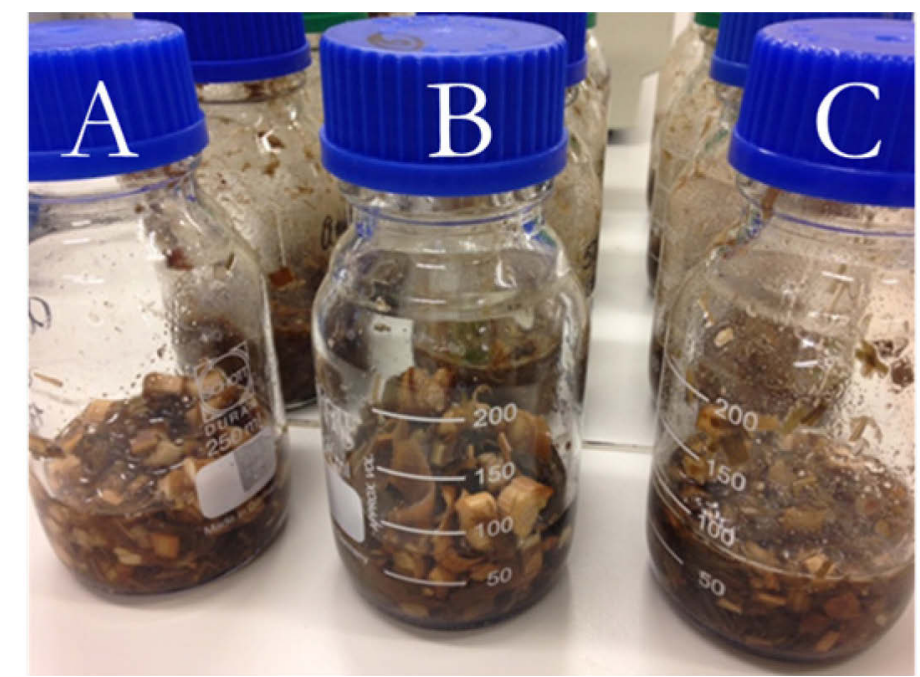

Figure 18 Ambrosini (A), 5 LG (B) and 10LG (C) before enzymatic hydrolysis but after acid pretreatment
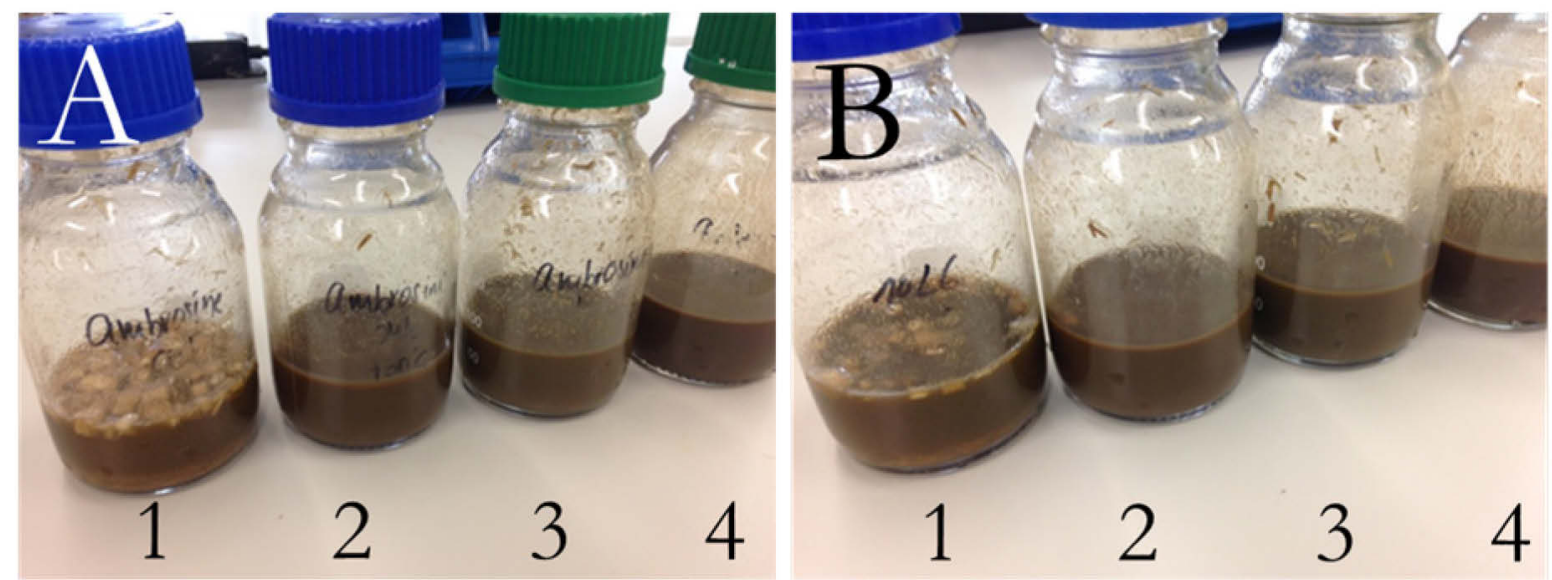

Figure 19 Ambrosini (left) and 10LG (right) after enzymatic hydrolysis, 5LG not shown 
After enzymatic treatment and centrifugation, the amount of monomeric sugars (glucose and xylose) was determined in the liquid phases. The yields of glucose and xylose after the heat treatment, acid hydrolysis and the enzymatic hydrolysis is illustrated in Figure 20 (glucose) and Figure 21 (xylose).

In general, most of the glucose was released due to the enzymatic hydrolysis. The glucose release after acid treatment (orange) was for each genotype comparable to the glucose release after heat and acid treatment (orange and blue). More severe pre-treatment at $160^{\circ} \mathrm{C}$ instead of $130^{\circ} \mathrm{C}$ gave a higher yield after enzymatic hydrolysis. The difference in yield between the two temperatures was the largest for Ambrosini.

Overall, acid treatment of $10 \mathrm{LG}$ at $160^{\circ} \mathrm{C}$ followed by enzymatic treatment resulted in the highest overall glucose yield (>90\%).

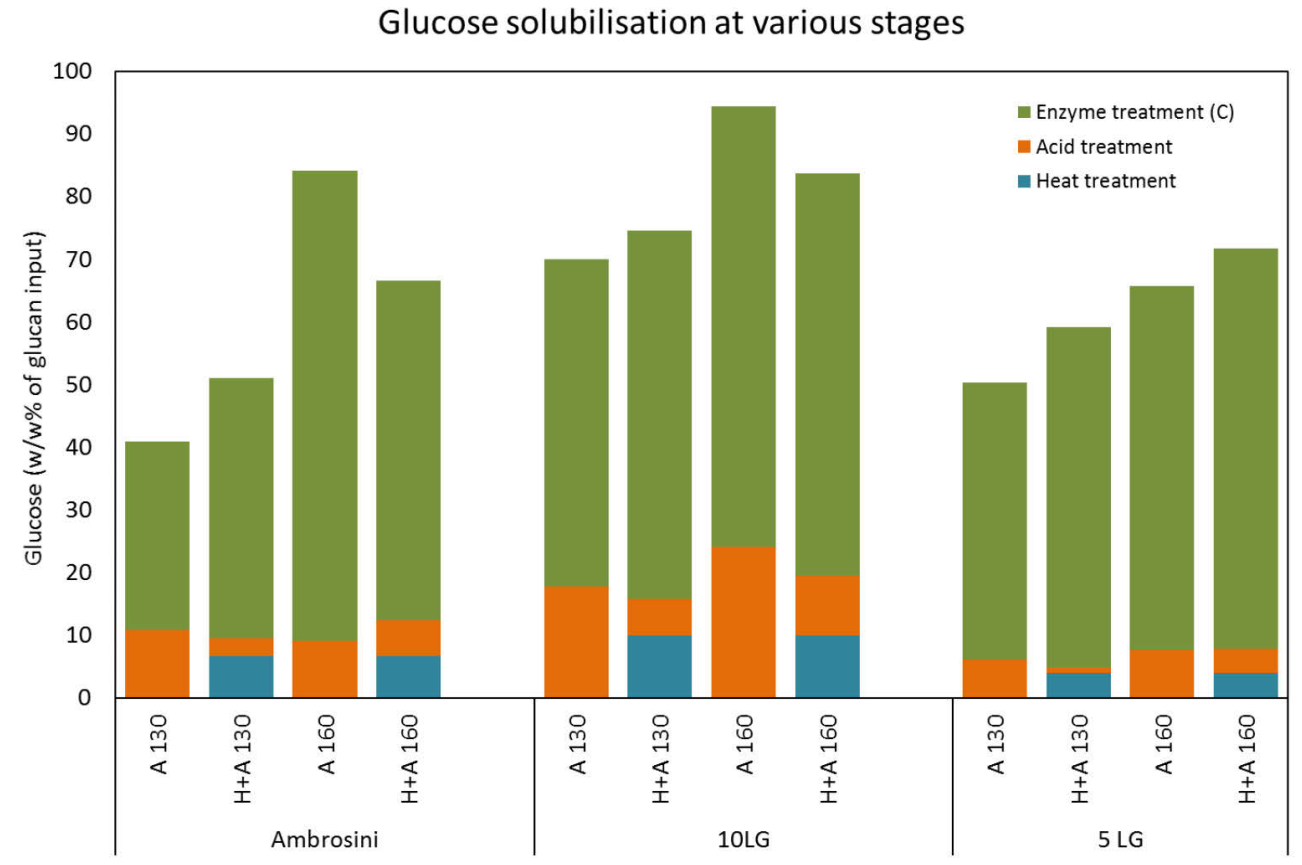

Figure 20 Glucose yields in w/w\% of glucan input after various processing steps

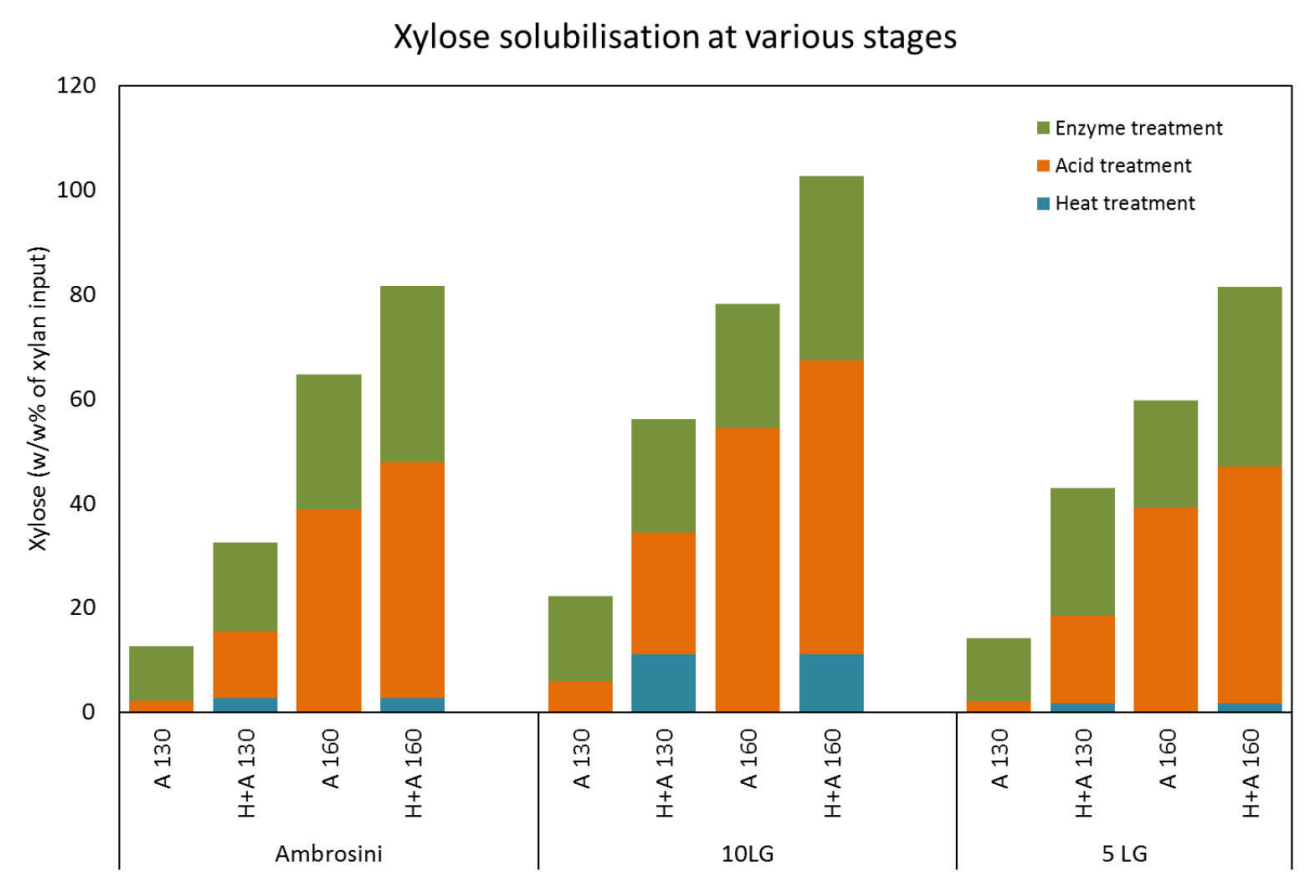

Figure $21 \quad$ Xylose yields in $w / w \%$ of glucan input after various processing steps

Figure 21 depicts the release of xylose. Increasing pre-treatment severity directly caused increased xylose solubilisation. Combined heat and acid treatment led to a much larger xylose solubilisation than 
acid treatment alone. After enzymatic hydrolysis over $80 \%$ xylose solubilisation was obtained with each maize genotype, $10 \mathrm{LG}$ gave the highest xylose release.

Acid treatment of $10 \mathrm{LG}$ at $160^{\circ} \mathrm{C}$ followed by enzymatic hydrolysis gave the highest yield, 24.g glucose and $16.4 \mathrm{~g}$ xylose per $100 \mathrm{~g}$ dry maize. At mild pre-treatment severity, the higher lignin content (see table 1) made Ambrosini the least digestible genotype. 10LG and 5LG were better digestible.

\subsubsection{Enzymatic hydrolysis of cellulose pulps}

The obtained cellulose pulps of treatment 2 (acid SHS), 3 (alkaline SHS) and 4 (alkaline) (as described in the previous paragraph) were also subjected to enzymatic hydrolysis for 24 and 72 hours with enzyme CTec 2 from Sigma. Figure 19-22 are pictures of the material before and after enzymatic hydrolysis.

Based on the results described in paragraph 3.2.4, the cellulose pulps of maize were high in cellulose content but (very) low in xylan content for the acid-SHS pulp. The alkaline pulps had a reduced lignin content, possibly beneficial for glucose release after enzymatic hydrolysis.

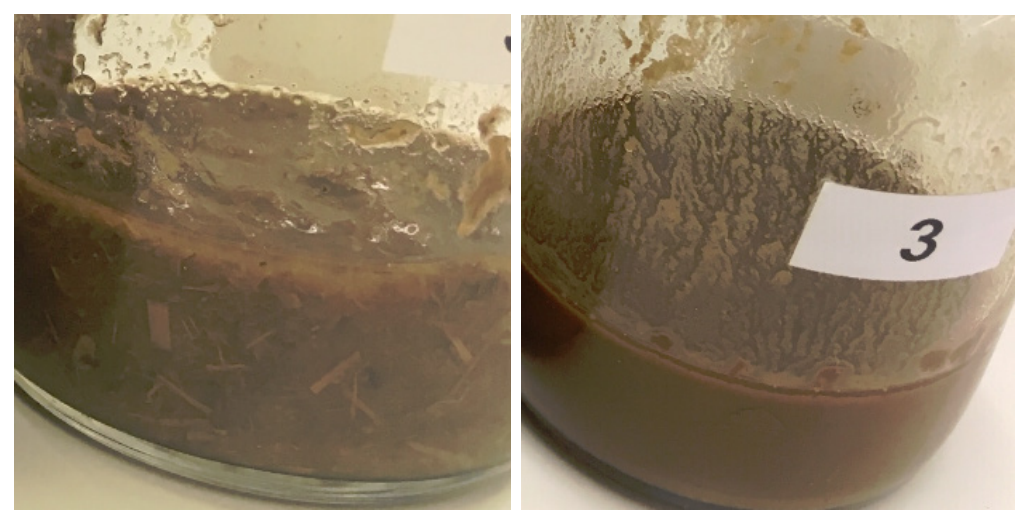

Figure 22 Acid SHS sample before enzymatic treatment (left picture) and after enzymatic treatment (right picture)

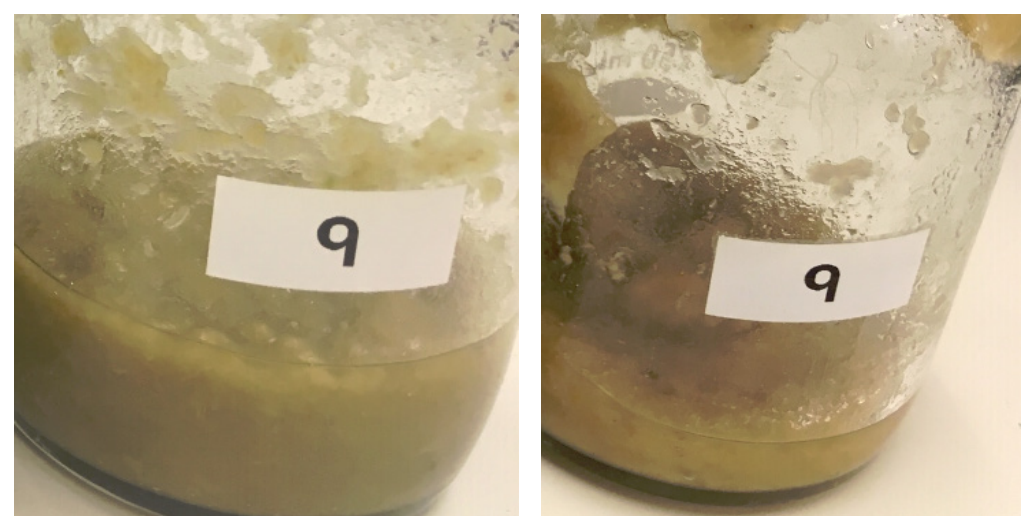

\section{Figure 23 Alkaline sample before enzymatic treatment (left picture) and after enzymatic treatment (right picture)}

After centrifugation the concentration of monomeric sugars (glucose and xylose) were determined in the liquid. The percentage of solubilised sugars was calculated from the amount of sugars present in the cellulose pulps after treatment (for composition see Figure 11), so not of the starting material. For glucose the results are shown in Figure 24, for xylose in Figure 25.

Overall the glucose and xylose yield after enzymatic hydrolysis was low. For glucose the acid treated sample released more sugars compared to the alkaline samples, while the initial glucose content was comparable. Acid treatment partly hydrolyses the cellulose, resulting in high sugar yields after enzymatic hydrolysis. But also the almost complete removal of hemicellulose might contribute to this. 
The acid SHS treatment was very successful in removing xylose form the biomass and an additional enzymatic hydrolysis was not required to release additional xylose. The alkaline treated samples did contain xylose but release due to the enzymatic hydrolysis was limited. The SHS-treated sample released more xylose than the alkaline sample.

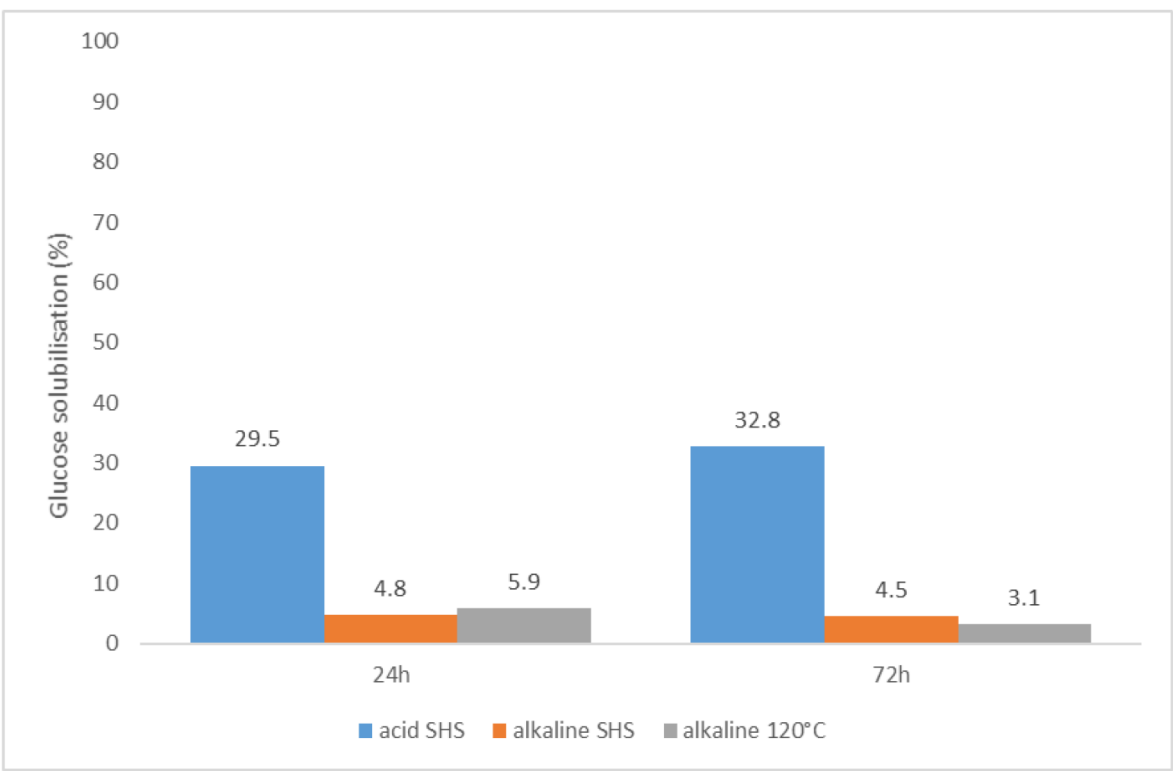

Figure 24 Glucose solubilisation after enzymatic treatment, measured after 24h and after $72 \mathrm{~h}$. Glucose solubilisation (\%) based on the amount of glucose present in the cellulose pulps after treatment

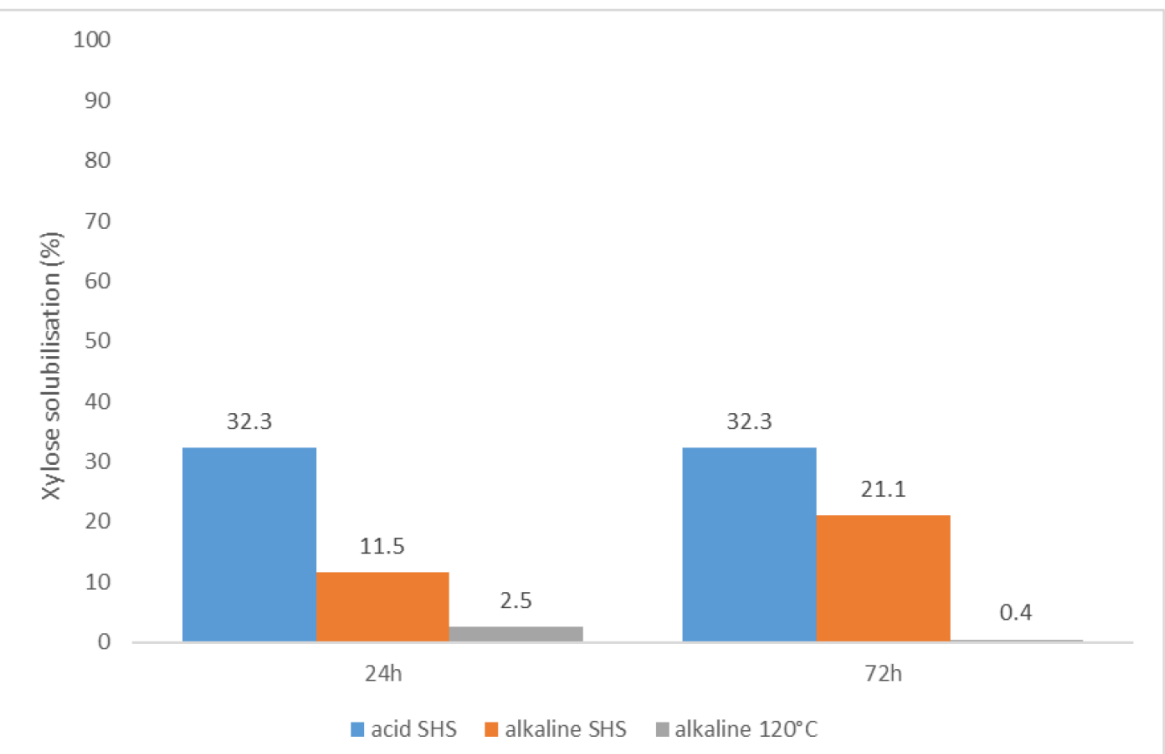

Figure 25 Xylose solubilisation after enzymatic treatment, measured after $24 h$ and after $72 \mathrm{~h}$. Xylose solubilisation (\%) based on the amount of xylose present in the cellulose pulps after treatment 


\section{Conclusions and recommendations}

Three genotypes of maize plants were provided by Wageningen Plant Research (Ambrosini, 10LG and $5 \mathrm{LG})$, varying in composition hemicellulose/cellulose/lignin. The samples were tested for their suitability as resource to produce sugars for fermentation, and the fibre quality was tested in the form of hand sheets prepared from the maize plants.

After harvesting and cutting of the maize plants, a heterogeneous mixture of stems and leaves was obtained with various particle sizes/thicknesses. Homogeneous samples for analysis purposes were prepared by mixing stems and leaves and milling it to a fine powder. Compared to other lignocellulosic biomasses these samples contained a high amount of water-soluble extractives, most likely due to soluble sugars that are present in the stems. The Ambrosini genotype contained the highest amount of lignin, 5LG sample the lowest.

\section{Fermentable sugars}

All three genotypes were subjected to an acid pretreatment at 130 or $160^{\circ} \mathrm{C}$, followed by enzymatic hydrolysis with a mixture of cellulases and hemicellulases. The treatment at $160{ }^{\circ} \mathrm{C}$ resulted in higher glucose and xylose yield compared to $130^{\circ} \mathrm{C}$, and especially for xylose the differences were large. Overall, genotype 5LG resulted in the lowest sugar yield, while genotype $10 \mathrm{LG}$ gave the highest yield.

From this part of the study it was concluded that maize plants are an interesting source of sugars, especially when the free sugars (found in the extractives) are included. It was recommended to extract the water-soluble sugars first to prevent sugar degradation of these free sugars in the pretreatment step. A subsequent acid pretreatment followed by enzymatic hydrolysis resulted in high yields (80-90\%) of sugars, leading to a theoretical sugar yield of approximately $50 \mathrm{wt} \%$ of the original biomass.

\section{Cellulose pulp}

Another part of the study was the conversion of the maize plants (genotype 5LG) to cellulose pulp by four different methods: prehydrolysis followed by organosolv, acid super heated steam (SHS), alkaline super heated steam, and alkaline pulping at $120^{\circ} \mathrm{C}$.

Retention of cellulose in the samples was the highest for the acid SHS treatment (91\%), but also the alkaline treatments resulted in a high retention of cellulose $(81 \%)$. For removal of hemicellulose the acid SHS treatment was by far the most efficient one. Under these conditions, only $4 \%$ of the hemicellulose remained in the sample and more than $90 \%$ was removed by the treatment. Cellulose content of the samples was $65 \mathrm{wt} \%$ for the acid-SHS treatment, and $58 \mathrm{wt} \%$ for the alkaline treatments, still far from $>90$ wt\% cellulose content required for a dissolving cellulose pulp.

For further research the composition of the liquid fraction after SHS and alkaline pulping needs to be analysed to see whether C5 sugars from hemicellulose were dissolved or further degradation to furfural and organic acids had occurred. For removal of lignin the alkaline processes were preferred, as in the acid SHS process no lignin was removed.

\section{Hand sheets}

The fibre properties of cellulose pulps and the mechanical- and physical properties of hand sheets were analysed. The cellulose-enriched samples were disintegrated, mechanically beaten and handsheets were prepared. The properties of these handsheets were determined to provide insight in the morphology of the pulps after chemical treatment, and on the performance for application in paper products.

Results showed that the acid-SHS treatment was less effective in breaking down the fibre bundles of the maize biomass into fibres compared to the alkaline treatments. The acid treated maize pulp was not fully disintegrated into fibres, resulting in a high bulk value. Also, the bulk levels of the alkaline 
treated pulps were at the higher side of chemical wood pulps, showing that the pulping treatments applied in this study were less severe than chemical pulping treatments of commercial pulps.

\section{Overall conclusions}

The value of cellulose pulps from maize stems and leaves was compared to commercial wood pulps and pulps made from nature grass. Overall, the quality of the maize pulps was low, and especially the acid-SHS treated samples had a very poor quality. Based on this study it was concluded that acidbased treatment processes are preferred for the production of sugars from maize stems and leaves, and that alkaline treatments are most suitable for the production of cellulose pulp. A second conclusion was that maize stems and leaves are a good biomass source for the production of sugars, and especially the 10LG genotype. 


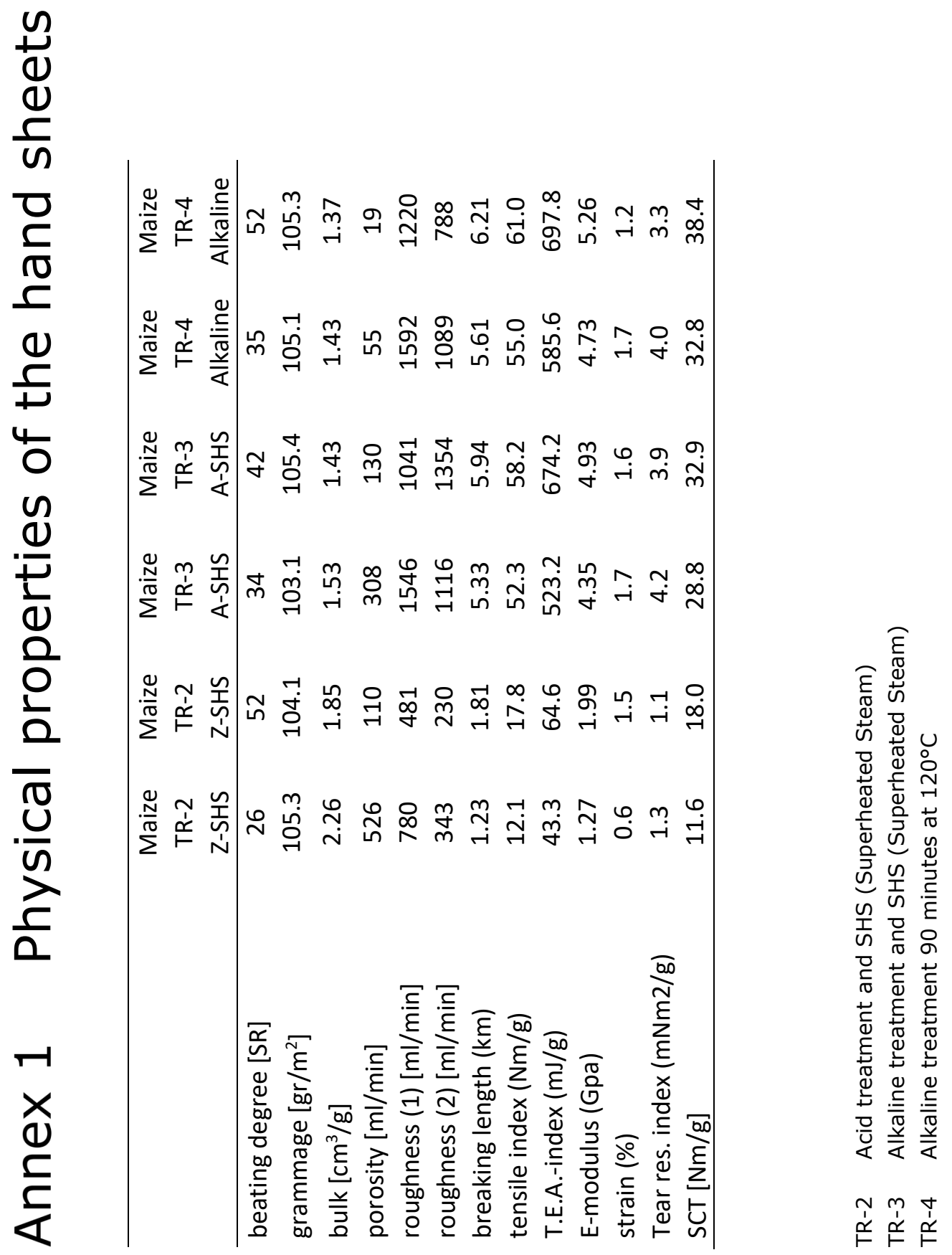






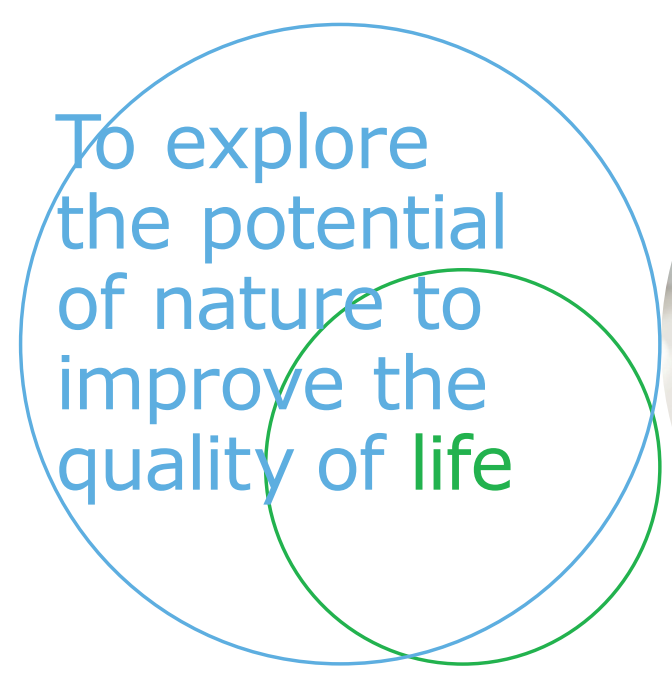

Wageningen Food \& Biobased Research Bornse Weilanden 9

6708 WG Wageningen

The Netherlands

www.wur.eu/wfbr

Einfo.wfbr@wur.nl

Report 2071

ISBN 978-94-6395-475-4

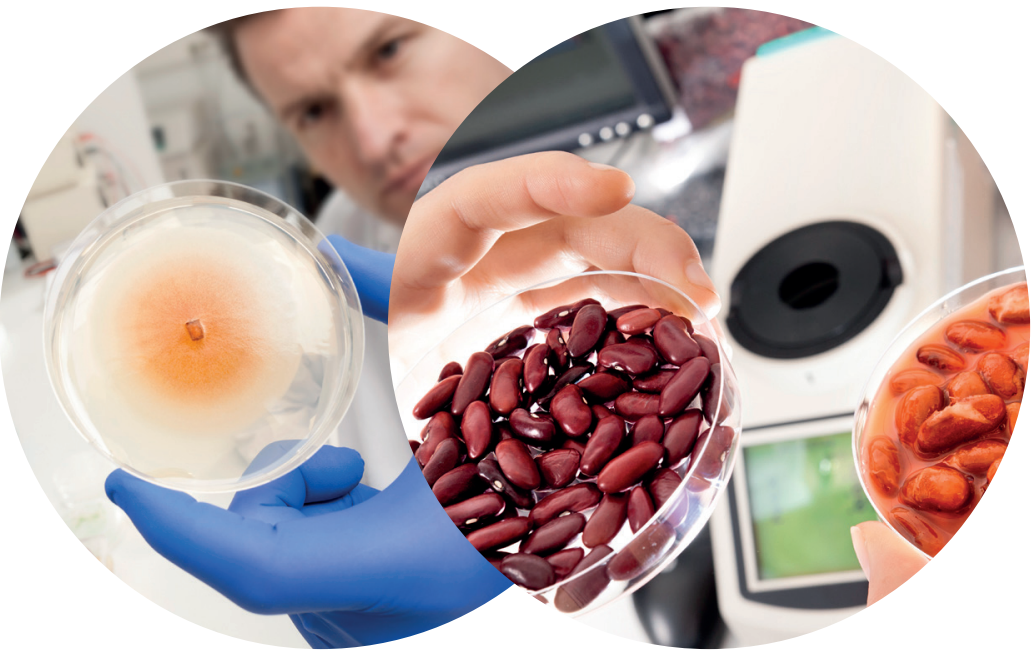

The mission of Wageningen University and Research is "To explore the potential of nature to improve the quality of life". Under the banner Wageningen University \& Research, Wageningen University and the specialised research institutes of the Wageningen Research Foundation have joined forces in contributing to finding solutions to important questions in the domain of healthy food and living environment. With its roughly 30 branches, 6,500 employees (5,500 fte) and 12,500 students, Wageningen University \& Research is one of the leading organisations in its domain. The unique Wageningen approach lies in its integrated approach to issues and the collaboration between different disciplines. 